\title{
A review of mixed-potential type zirconia-based gas sensors
}

\author{
Norio Miura • Tomoaki Sato • Sri Ayu Anggraini • \\ Hiroshi Ikeda $\cdot$ Serge Zhuiykov
}

Received: 3 April 2014 / Accepted: 23 April 2014 / Published online: 28 May 2014

(C) The Author(s) 2014. This article is published with open access at Springerlink.com

\begin{abstract}
A robust and reliable gas sensing device is considered as a convenient and practical solution for gas concentration monitoring that has become a mandatory requirement in different field of applications. For in situ hazardous gases detection, a mixed-potential type gas sensor has been regarded as a promising solid-state gas sensor. For the past three decades, there has been a significant progress in achieving high performance in mixed-potential type sensors. Therefore, this review is focused on reporting the development of mixedpotential type gas sensors with combined yttria-stabilized zirconia (YSZ) as the base solid electrolyte material and various classes of electrode materials for their potential utilization as a high-performance sensing electrode. The underlying sensing mechanism of a mixed-potential type YSZ-based sensor is elaborated here in detail. Transformation in design and configuration of this type of sensor is also covered in this report. In addition, recent progresses on mixed-potential type gas sensors development for detection of several target gases, such as carbon monoxide, hydrocarbons, nitrogen oxides, hydrogen, and ammonia, are reviewed. Strategies to improve the sensing characteristic, particularly gas sensitivity and selectivity, are also reported. Based on the understanding of the fundamental sensing mechanism and the requirements for
\end{abstract}

N. Miura $(\bowtie) \cdot$ T. Sato $\cdot$ S. A. Anggraini $\cdot$ H. Ikeda $\cdot$ S. Zhuiykov Art, Science and Technology Center for Cooperative Research, Kyushu University, Kasuga, Fukuoka 816-8580, Japan

e-mail: miurano@astec.kyushu-u.ac.jp

T. Sato

Japan Society for the Promotion of Science, Chiyoda-ku,

Tokyo 102-8471, Japan

\section{S. Zhuiykov}

Materials Science and Engineering Division, Commonwealth

Scientific Industrial Research Organization, 37 Graham Road, Highett, Melbourne, VIC 3190, Australia high-performance gas sensors, challenges and future trends for this type of gas sensor development are discussed.

Keywords Mixed potential · Electrochemical sensor · Gas sensor $\cdot$ Solid electrolyte $\cdot$ Automotive exhausts $\cdot$ Air pollutants

\section{Introduction}

Awareness of automatic and accurate monitoring of environmental pollutants from automobiles and other different industrial sources has been increased recently due to the fast development of several emerging economies. The speed of such industrialization has firmly confirmed that the automotive industries expand with accelerating rate every year not only in the advance but also in the developing countries. Therefore, strict regulations have to be implemented to reduce the pollutants [1-3]. In this regard, the development of low-cost, miniaturized, reliable, and robust environmental sensors for measurement of various toxic gases is an ongoing process. Notwithstanding great progress in science, technology, and commercialization of the chemical sensors during recent years and the growing public concern of the hazards of many airborne chemicals, new ranges of the sensitive and selective sensors with faster response are required, which can address the toughening requirements to air pollutants in most of the developed countries.

The major hazardous gases in air are commonly carbon monoxide (CO), hydrocarbons ( $\mathrm{HCs})$, nitrogen oxides $\left(\mathrm{NO}_{x}\right)$, hydrogen $\left(\mathrm{H}_{2}\right)$, ammonia $\left(\mathrm{NH}_{3}\right)$, sulfur dioxide $\left(\mathrm{SO}_{2}\right)$, and hydrogen sulfide $\left(\mathrm{H}_{2} \mathrm{~S}\right)$ [4-8]. Thus, tough environmental legislation is being enforced in relation to the emissions from automotive transport in Europe, USA, and Japan. For example, based on Euro VI (2014) legislation, the low limit values for $\mathrm{CO}, \mathrm{NO}_{x}$, and total $\mathrm{HCs}$ were set to be 1.0, 0.060, and 
$0.10 \mathrm{~g} / \mathrm{km}$, respectively, for passenger cars using gasoline [9]. These low limits require the advanced in situ emissions monitoring in exhausts to ensure further development of ultra-lowemission vehicles.

One of the most practical and reliable sensors among detecting devices commercialized for automotive industries is potentiometric $\lambda$-sensor based on yttria-stabilized zirconia (YSZ) attached with Pt sensing electrode (SE) [10]. It has about 40 years of history and experience working on gasolinebased vehicles worldwide. Therefore, YSZ has been proven as one of the best sensor's materials. Another example is a YSZbased amperometric $\mathrm{NO}_{x}$ sensor for automotive exhausts, which has recently been commercialized by NGK (Japan) $[11,12]$. Consequently, considering an excellent chemical and mechanical stability of YSZ and its good adhesive property over a long period of time, this material has also a great potential for measurement of toxic gases [7, 9]. The practical advantage of the YSZ-based gas sensors is that they can be fabricated either in planar or tubular configuration. Thus, the selection of proper SE materials together with optimization of their thickness and morphology has been confirmed as key parameters for achieving desirable sensing characteristics to a target pollutant $[9,13]$.

Although many potentiometric [14-18], amperometric [19-23], and impedancemetric [24-28] YSZ-based gas sensors have been reported so far, mixed-potential type gas sensors have been receiving the great attention among researchers during the last decades, owing to their special capability to measure low concentrations of pollutant gases in car exhausts or atmospheric air in the wider operating temperature range of $450-900{ }^{\circ} \mathrm{C}[9,29,30]$. The abnormal phenomenon of potential signal in the gas mixture containing air and fuel for a zirconia-based oxygen sensor has been first observed by Fleming and Pebler in 1977 [31], calling it the non-Nernstian behavior. The calcia-stabilized zirconia (CSZ)-based sensors attached with different noble metal-SEs were reported by Shimizu et al. in 1978 for detection of various reducing gases ( $\mathrm{CO}, \mathrm{HCs}$, and $\mathrm{H}_{2}$ ) at $550-600{ }^{\circ} \mathrm{C}$ [32], without full understanding what caused the non-Nernstian behavior of the sensor. Then, the concept of mixed-potential has been suggested by Okamoto et al. in 1980 and 1981 [33, 34] for the YSZbased $\mathrm{CO}$ sensor using Pt-SE coated with $\mathrm{Al}_{2} \mathrm{O}_{3}(+\mathrm{Pt})$ or $\mathrm{SnO}_{2}$ catalyst layer, operated at rather lower temperature of $300{ }^{\circ} \mathrm{C}$. Further developments of this type of sensor based on nonNernstian potential using noble metal-based SEs, such as Pt$\mathrm{SE}, \mathrm{Mo}$ (or Pt alloy)-SE, catalyst layer/Pt-SE, $\mathrm{RuO}_{2}$-SE, and Pt-SE for detection of HCs ( or CO), were reported by Moseley and Tofield in 1987 [35], Vogel et al. in 1993 [36], Tan et al. in 1993 and 1994 [37, 38], Narducci et al. in 1994 [39], and Can et al. in 1995 [40], respectively. Moreover, the important improvements in sensing capabilities of the mixed-potential type YSZ-based gas sensors were achieved by Mcaleer et al. in 1989 [41, 42], Miura et al. in 1995 [43] and 1996 [44-47], and Jakobs et al. in 1996 [48], by replacing the noble metalbased SEs with inexpensive oxide-SEs. For example, $\mathrm{SnO}_{2}$, spinel-type oxides, $\mathrm{WO}_{3}$, and $\mathrm{ZnO}$ were utilized as SE materials for the mixed-potential type gas sensors to detect reducing gases [41, 42], $\mathrm{NO}_{x}[44,45], \mathrm{H}_{2} \mathrm{~S}[43,46]$, and $\mathrm{H}_{2}$ [47], respectively. In 1996 and 1997, Sorita and Kawano have also reported the YSZ-based sensor using various mixed oxides (e.g., perovskite and spinel) as $\mathrm{SE}$ coated with an $\mathrm{Al}_{2} \mathrm{O}_{3}(+\mathrm{Pt})$ catalyst layer for selective detection of $\mathrm{CO}\left(\right.$ or $\left.\mathrm{H}_{2}\right)[49,50]$. Since then, substantial development of this type of gas sensors has been achieved early in this century by many leading research groups in the world [51-64].

On the other hand, the mixed-potential type $\mathrm{H}_{2}$ (or $\mathrm{CO}$ ) sensors based on proton $\left(\mathrm{H}^{+}\right)$conductive solid electrolytes such as Nafion membrane, zirconium phosphate, antimonic acid, etc. have been first reported by Miura et al. in 1982-1992 [65-69]. These sensors can be operated potentiometrically (or amperometrically) at room temperature and detect low concentrations of $\mathrm{H}_{2}$ (or $\mathrm{CO}$ ) diluted with air [69]. Based on the initial results, the battery-driven cordless $\mathrm{CO}$ sensors based on proton conductors (or $\mathrm{OH}^{-}$conductors) have been commercialized [70,71]. Nowadays, around ten million of this type of sensor is estimated to be sold in USA for the purpose of prevention of $\mathrm{CO}$ poisoning in houses.

Mixed-potential concept pertains to the situation where more than two electrode reactions occur on SE. The mixedpotential can be generated when the cathodic current is equal with the anodic current; hence, the net current at mixedpotential is zero. The generated mixed-potential does not correspond with the thermodynamic equilibrium potential that follows Nernst equation for the involved electrochemical reaction. In contrast to the equilibrium SE potential, the value generated by mixed potential depends on the kinetics of various reactions including both of the interfacial electrochemical reactions at the SE/solid electrolyte interface and the heterogeneous gas-phase reactions through the SE layer. The SE material (type, grain size, orientation, porosity, morphology) and the state of the oxide-SE/YSZ interface are the key factors in establishment of mixed-potential. Examination and optimization of all these factors leads to the enhancement of sensing performances of the mixed-potential type sensors toward target gases.

In this paper, the recent advancements of the mixedpotential type zirconia-based sensors for several hazardous gases will be comprehensively and assiduously reviewed from the viewpoint of environmental monitoring and on-board vehicles' diagnosis.

\section{Sensor configuration}

The configuration of mixed-potential type YSZ-based gas sensor can basically be classified into two types: planar and 
tubular ones. The schematic view of a simple planar YSZbased sensor is shown in Fig. 1a. In this configuration, a YSZ plate is usually attached with SE and a Pt reference electrode (RE) on the opposite or same side of the YSZ plate. A Pt current collector is located in between SE and YSZ, and a Pt lead wire is connected to Pt-RE. In order to avoid the contact of Pt with YSZ, a non-conducting material is formed between the Pt current collector and YSZ. A sensing signal of the device is obtained by measuring a potential difference (emf) between SE and RE. The advantage of the planar sensor is simplicity of configuration which enables easy miniaturization. However, it should be noted that the potential value of Pt$\mathrm{RE}$ is affected by the change in $\mathrm{O}_{2}$ concentration and by the existence of relatively high concentrations of various untarget gases, at lower operational temperatures. As an alternative, Miura et al. have recently reported that the $\mathrm{Mn}_{2} \mathrm{O}_{3}-\mathrm{RE}$ exhibited insensitivity to the variations of $\mathrm{O}_{2}$ concentration within the range of $0.1-21 \mathrm{vol} \%$ as well as to various gas at temperatures below $550{ }^{\circ} \mathrm{C}$, as shown in Fig. 2 [72, 73]. It can potentially replace Pt-RE in this type of gas sensors.

On the other hand, a tubular YSZ-based sensor has a different design (Fig. 1b). In this case, only SE is exposed to the sample (target) gases, while Pt-RE is always open to an atmospheric air, in order to construct Pt/air-RE. Thus, the configuration of a tubular sensor is relatively complex and bulky, compared with the planar sensor. However, it is quite advantageous that the potential behavior of SE is always observed independently since the SE side is separated from the Pt/air-RE side by means of a YSZ tube itself. In fact, the commercialized YSZ-based $\lambda$ sensor for car exhausts is usually constructed by using a tubular configuration [74].

In both planar and tubular YSZ-based sensors reported so far, a dense YSZ plate (or tube) and a porous SE layer have usually been utilized. Sample gases can pass through the porous SE layer and reach the SE/YSZ interface where a sensing signal is generated. It is well known that a part of sample gas is oxidized (or decomposed) during the diffusion process by a heterogeneous gas-phase reaction [9, 15, 75-77]. This causes the decrease in concentration of the sample gas reaching the SE/YSZ interface and consequently lowers the sensor's sensitivity. However, the catalytic reaction may play an important role in achieving a good selectivity by taking the advantage of the difference in a catalytic activity to the gasphase reaction involving each target gas. Unlike the conventional sensors, Garzon et al. have proposed a unique sensor which is composed of a porous YSZ and a dense SE plate, as displayed in Fig. 1c [78, 79]. In such a sensor geometry, sample gases mainly pass through the porous YSZ layer and reach the SE/YSZ interface. Considering that the heterogeneous catalytic activity of YSZ is usually low, the heterogeneous reactions of sample gases proceed less during the diffusion process. This sensor's design resulted in the increase of (a)

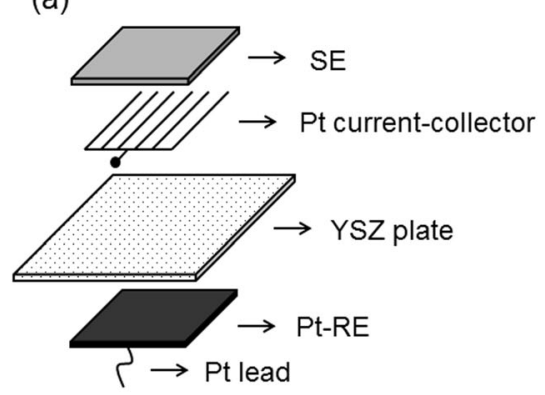

(b)

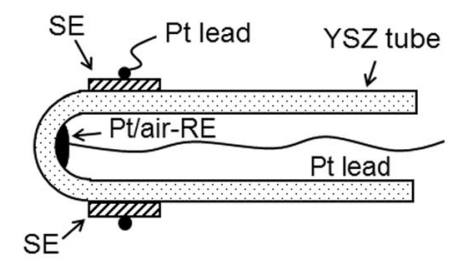

(c)

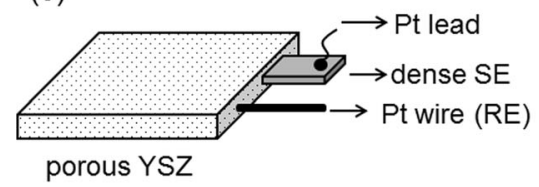

(d)

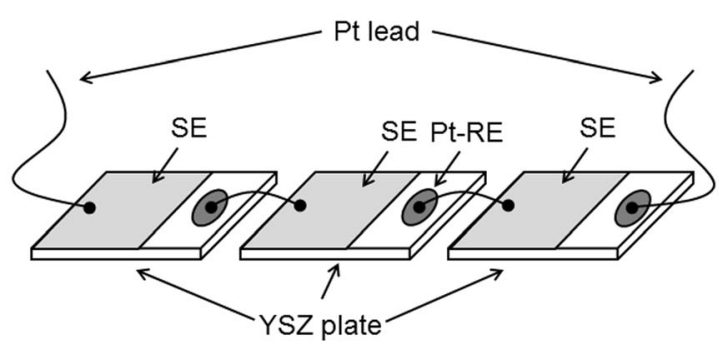

(e)

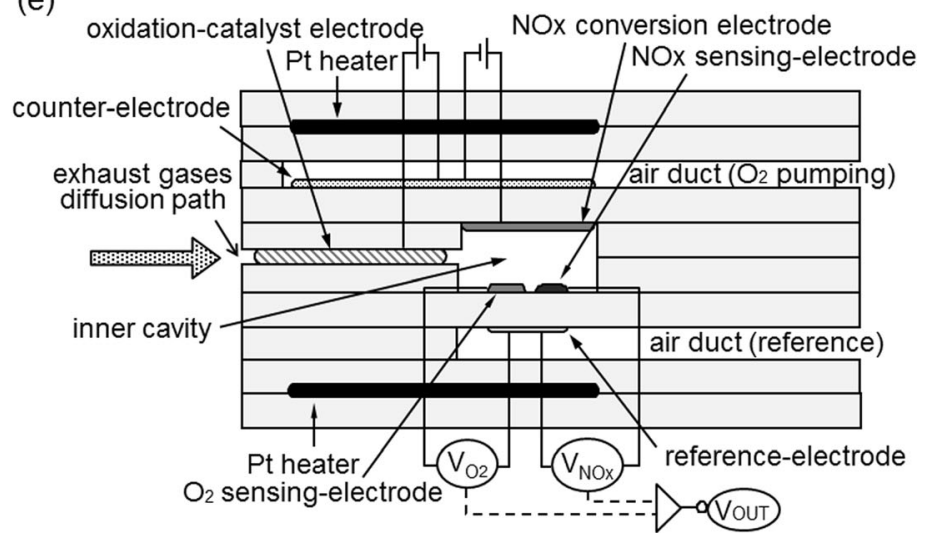

Fig. 1 Schematic views of various mixed-potential type YSZ-based sensors: a planar; b tubular; c combination of porous YSZ and dense SE; d threesensor array; and e laminated total- $\mathrm{NO}_{x}$ sensor. [Adapted from [79, 80, 82], Copyright 2012, 2007, and 2004, with permission from Elsevier] 

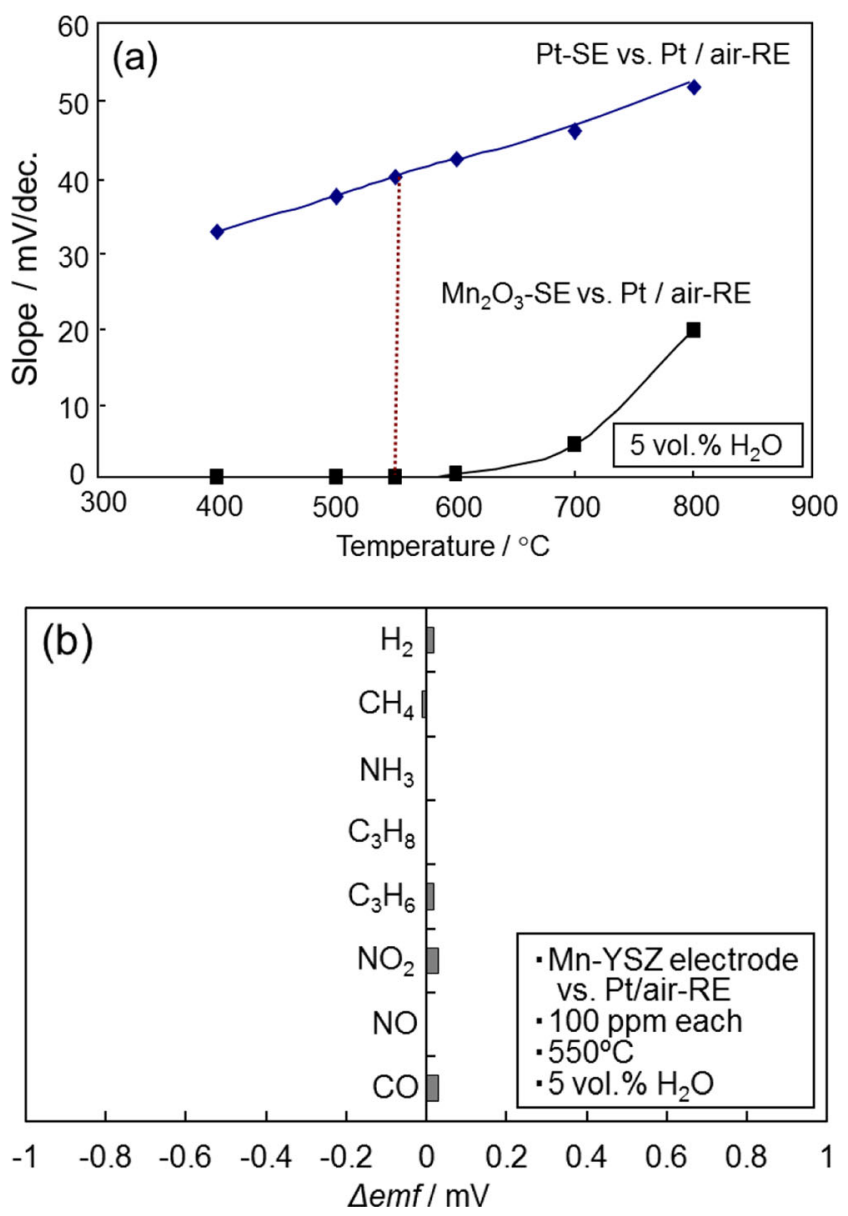

Fig. 2 a Slope for oxygen concentration dependence of emf evaluated at various operating temperatures, for the tubular sensor attached with the outer Pt- and $\mathrm{Mn}_{2} \mathrm{O}_{3}$-SEs (vs. the inner Pt/air-RE). b Sensitivity ( $\Delta$ emf) of the sensor utilizing $\mathrm{Mn}_{2} \mathrm{O}_{3}$ (Mn-YSZ) electrode and Pt/air-RE toward different exhaust gases at $600{ }^{\circ} \mathrm{C}$. [Reproduced from [72, 73], Copyright 2010 and 2012, with permission from Elsevier and The Electrochemical Society]

gas sensitivity, despite the fact that the screening of the specific gas by the catalytic reaction through the SE layer was not enabled. Thus, in this sensor configuration, only the electrochemical catalytic activities at the SE/YSZ interface can control the sensing characteristics, unlike the normal sensor using a dense YSZ and a porous SE layer whose sensing characteristics are governed by both of the heterogeneous catalysis and the electrochemical catalytic activities.

One of the advantages of the mixed-potential type sensor is an ability to have a connection of the several planar sensors into one sensor design. The example of such a design reported by Yang and Dutta is presented in Fig. 1d [80]. In this case, the total value of emf for the integral sensor is obtained by multiplying each emf value by the number of sensors. The increase in a number of sensors resulted in the lowering of the detection limit of a target gas, while the entire measuring device became complex and bulky.
Figure 1e shows the cross-sectional view of the laminated-type YSZ-based total $\mathrm{NO}_{x}$ sensing system designed for automobile application, reported by Hasei et al. [81, 82]. In this sensor configuration, oxygen gas is continuously supplied from a counter electrode (CE) side to an oxidation catalyst electrode by applying voltage between these two electrodes. Reducing gases (such as $\mathrm{HCs}$ and $\mathrm{CO}$ ), which pass through a diffusion path, react with oxygen on the surface of oxidation catalyst, forming non-interference gases $\left(\mathrm{H}_{2} \mathrm{O}\right.$ and $\left.\mathrm{CO}_{2}\right)$. In the same manner, the $\mathrm{NO}$ conversion electrode, located on the upper side of an inner cavity, oxidizes $\mathrm{NO}$ to $\mathrm{NO}_{2}$. Thus, the total $\mathrm{NO}_{x}$ concentration can be measured by a mixed-potential type $\mathrm{NO}_{2}$ sensor (electrode) settled on the bottom of the cavity.

\section{Sensing mechanism}

The underlying sensing mechanism of a mixed-potential type sensor can be explained by using a YSZ-based $\mathrm{H}_{2}$ sensor as a simple example. Figure 3 a illustrates typical arrangement of a mixed-potential type YSZ-based sensor, which consists of SE exposed to the sample gas and RE exposed to the reference gas (air). When SE is exposed to the base gas (air), the electrochemical reaction (1) of $\mathrm{O}_{2}$ is equilibrated at the SE/YSZ interface. In this case, the potential value of SE can be determined by the equilibrium state of reaction (1) in the base gas (air), and the emf between SE and RE gives a base line (signal) of the sensor. On the other hand, when the sample gas (in this case $\mathrm{H}_{2}$ ) diluted with the base gas is allowed to flow over SE, a different phenomenon occurs. A mixed potential can be generated, when a steady-state condition is achieved by the two electrochemical reactions: the anodic reaction (2) of $\mathrm{H}_{2}$ and the cathodic reaction (3) of $\mathrm{O}_{2}$, at the SE/YSZ interface (Fig. 3b). Simultaneously, since RE is always exposed to reference gas (air), an equilibrium reaction (1) of $\mathrm{O}_{2}$ that occurs at the interface of RE/YSZ will also generate a potential (Fig. 3c). Then, emf (potential difference between SE and RE) gives a sensing signal of the sensor. However, before reaching the SE/YSZ interface, some percentage of the sample gas diffusing through the SE layer will be oxidized within the SE layer via gas-phase reaction (4) (Fig. 3d). Hence, the reactivity to gas-phase oxidation of $\mathrm{H}_{2}$ can also control the number of gas species capable of reaching the YSZ/SE interface. Therefore, the $\mathrm{H}_{2}$ sensitivity of a mixed-potential type sensor can be determined by the balance of three catalytic activities of an SE material toward anodic reaction (2) of $\mathrm{H}_{2}$, the cathodic reaction (3) of $\mathrm{O}_{2}$ and the gas-phase reaction (4) of $\mathrm{H}_{2}$. Since these catalytic activities will be largely 
Fig. 3 Illustration of a the typical construction of a mixed-potential type YSZ-based sensor, including b the electrochemical reactions that occur at the SE/YSZ interface and $\mathbf{c}$ the equilibrium $\mathrm{RE}$ reaction of $\mathrm{O}_{2}$ at the interface of $\mathrm{RE} / \mathrm{YSZ}$, as well as $\mathbf{d}$ the gas-phase oxidation (heterogeneous catalysis) within the SE layer (b)

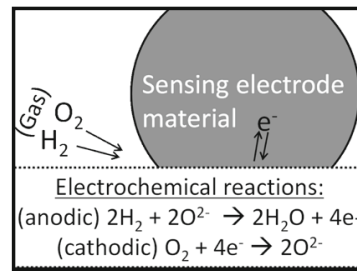

(YSZ) $\uparrow \downarrow$

(a)

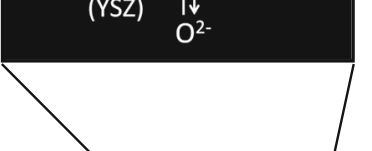

Sample gas $\mathrm{H}_{2}$<smiles>O=C1CCCCC1</smiles>

(d)

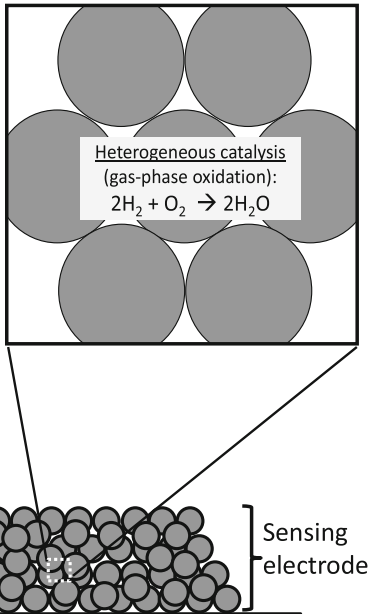

(c)

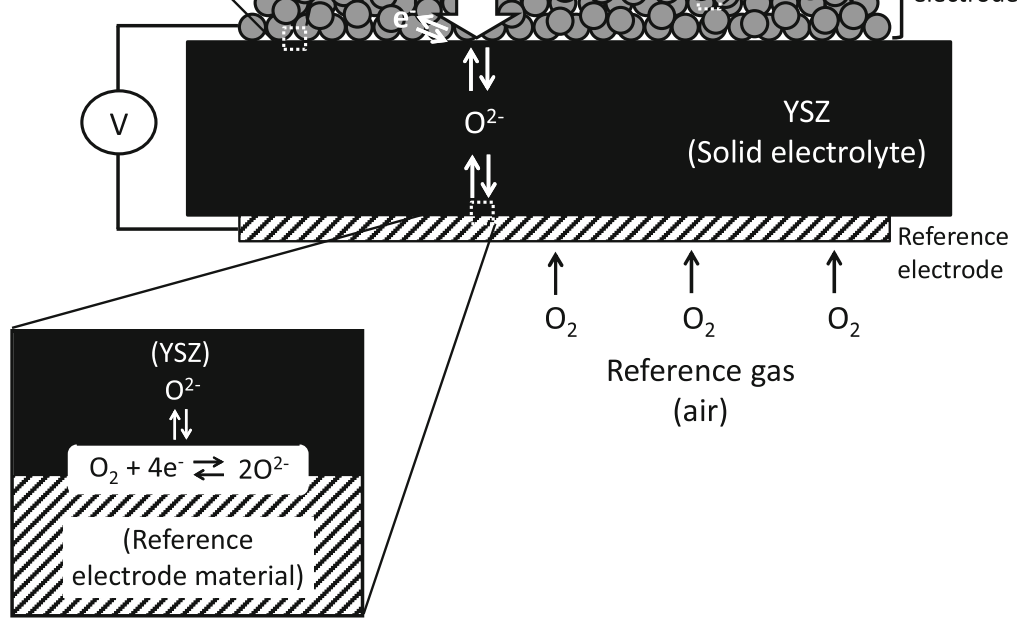

governed by the physical/chemical properties of an SE material, SE composition/design and the operating conditions of the sensor, the gas sensitivity of mixedpotential type sensor can also be determined by the above-mentioned factors.

$\mathrm{O}_{2}+4 \mathrm{e}^{-} \rightleftarrows 2 \mathrm{O}^{2-}$

$2 \mathrm{H}_{2}+2 \mathrm{O}^{2-} \rightarrow 2 \mathrm{H}_{2} \mathrm{O}+4 \mathrm{e}^{-}$

$\mathrm{O}_{2}+4 \mathrm{e}^{-} \rightarrow 2 \mathrm{O}^{2-}$

$2 \mathrm{H}_{2}+\mathrm{O}_{2} \rightarrow 2 \mathrm{H}_{2} \mathrm{O}$ explained according to Butler-Volmer equation [46, 83-85]. Each current density for reactions (2) and (3) is expressed as Eqs. (5) and (6), respectively:

$$
i_{\mathrm{H}_{2}}=i_{\mathrm{H}_{2}}^{0} \exp \left\{2 \alpha_{1} F\left(E-E_{\mathrm{H}_{2}}^{0}\right) / R T\right\}
$$

$$
i_{\mathrm{O}_{2}}=i_{\mathrm{O}_{2}}^{0} \exp \left\{-4 \alpha_{2} F\left(E-E_{\mathrm{O}_{2}}^{0}\right) / R T\right\}
$$

where $E$ is the electrode potential, $F$ is Faraday constant, $R$ is the molar gas constant, $T$ is the absolute temperature, $E^{0}$ is the equilibrium electrode potential, $i^{0}$ is the exchange current density, and $\alpha$ is the transfer coefficient. Here, the exchange current densities in Eqs. (5) and (6) are assumed to obey the following relations (Eqs. (7) and (8)).

$i_{\mathrm{H}_{2}}^{0}=B_{1} C_{\mathrm{H}_{2}}^{m}$

$i_{\mathrm{O}_{2}}^{0}=-B_{2} C_{\mathrm{O}_{2}}^{n}$
Miura et al. and Garzon et al. have reported that the emf response of the mixed-potential type sensor can be 
where $C$ is the concentration of $\mathrm{H}_{2}$ or oxygen, and $B_{1}, B_{2}, m$, and $n$ are constants. The mixed potential $\left(E_{m}\right)$ is defined as the electrode potential at which the absolute values of current densities in Eqs. (5) and (6) are equal, as shown in Fig. 4a. In this figure, the diffusion of $\mathrm{H}_{2}$ in the $\mathrm{SE}$ layer is postulated to be a rate-determining step (diffusion limited). By using Eqs. (5)-(8), $E_{m}$ can be expressed as Eq. (9). Here, $E_{0}$ and $A$ in Eq. (9) are given in Eqs. (10) and (11), respectively [46, 83-85]. In the case of the diffusion limited, the current for the anodic reaction of $\mathrm{H}_{2}$ can be expressed as Eq. (12), where $A$ is the electrode area, $D$ is the diffusion coefficient, and $\delta$ is the diffusion boundary layer thickness. Thus, by using Eqs. (5)-(8) and (12), $E_{m}$ can be expressed as Eq. (13).

$E_{m}=E_{0}+n A \ln C_{\mathrm{O}_{2}}-m A \ln C_{\mathrm{H}_{2}}$

$E_{0}=\frac{R T}{\left(4 \alpha_{1}+2 \alpha_{2}\right) F} \ln \frac{B_{1}}{B_{2}}+\frac{2 \alpha_{1} E_{\mathrm{O}_{2}}^{0}+\alpha_{2} E_{\mathrm{H}_{2}}^{0}}{2 \alpha_{1}+\alpha_{2}}$

(a)

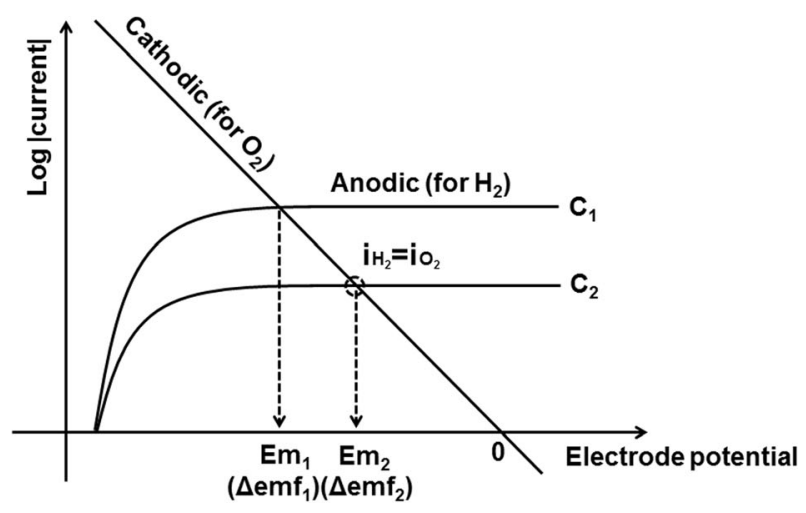

(b)

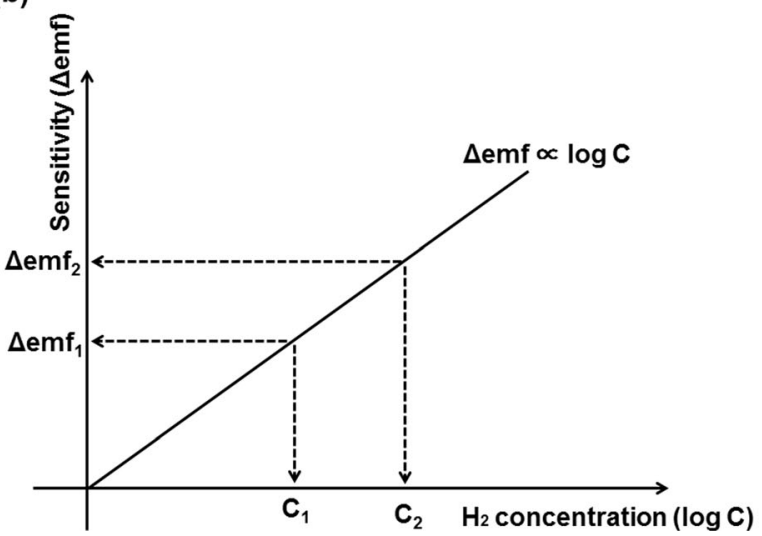

Fig. 4 a Estimation of mixed-potential value from the intersection between the diffusion-limited anodic polarization curve of $\mathrm{H}_{2}$ and the cathodic polarization curve of $\mathrm{O}_{2} ; \mathbf{b}$ dependence of the sensitivity $(\Delta \mathrm{emf})$ on the logarithm of $\mathrm{H}_{2}$ concentration
$A=\frac{R T}{\left(4 \alpha_{1}+2 \alpha_{2}\right) F}$

$i_{\mathrm{H}_{2}}=2 F A D_{\mathrm{H}_{2}} \frac{C_{\mathrm{H}_{2}}}{\delta}$

$E_{m}=E_{\mathrm{O}_{2}}^{0}-\frac{R T}{4 \alpha_{2} F} \ln \frac{2 F A D_{\mathrm{H}_{2}} C_{\mathrm{H}_{2}}}{B_{2} C_{\mathrm{O}_{2}}^{n} \delta}$

Thus, as theoretically seen from Eq. (9) and (13), the simple linear relationship between $E_{m}$ and the logarithm of $\mathrm{H}_{2}$ concentration $\left(E_{m} \propto \log C_{\mathrm{H}_{2}}\right)$ can be observed when the oxygen concentration is fixed (Fig. $4 b$ ).

The above-mentioned sensing mechanism of a mixedpotential type sensor (e.g., $\mathrm{H}_{2}$ sensor) can be rationalized by using general polarization curves (Fig. 5a). In this case, the intersect point of the modified anodic and modified cathodic polarization curves is also assigned as mixed potential $\left(E_{m}\right)$. The modified cathodic polarization curve is obtained by plotting the applied potential with the absolute current value of the base gas (air). The modified anodic polarization curve is obtained by plotting the applied potential with the net anodic current of $\mathrm{H}_{2}$. The net anodic current of $\mathrm{H}_{2}$ is calculated by subtracting the recorded current value in the base gas (air) from the current value measured in the sample gas $\left(\mathrm{H}_{2}+\right.$ air).

Changes in catalytic activities against the gas-phase reactions and/or electrochemical reactions can also be elucidated by the measurements of polarization curves (Fig. 5b) [86]. When the polarization curve is measured in the sample gas diluted with the base gas, the recorded anodic current is proportional to the number of gaseous molecule that undergoes the electrochemical reactions at the SE/YSZ interface. Under this condition, the heterogeneous catalysis that usually occurs within the SE layer will reduce some percentage of the $\mathrm{H}_{2}$ molecules passing through the SE layer, resulting in lower anodic current. However, in the absence of $\mathrm{O}_{2}$ (in $\mathrm{N}_{2}$ ), all $\mathrm{H}_{2}$ molecules will reach the SE/YSZ interface to proceed the electrochemical reaction, resulting in higher anodic current. Therefore, the anodic polarization curve that measured in $\mathrm{N}_{2}$ will represents the net catalytic activity toward anodic reaction (2) of $\mathrm{H}_{2}$ at the SE/YSZ interface. The difference between the polarization curves measured in each of $\mathrm{N}_{2}$ and air is believed to correspond to the catalytic activity of gas-phase reaction (4) (Fig. 5b).

From the perspective of a mixed-potential model, higher gas sensitivity can be achieved by one or the combination of the following conditions: an increase in the catalytic activity to the anodic reaction (2) of the target gas $\left(\mathrm{H}_{2}\right)$, a decrease in the 
(a)

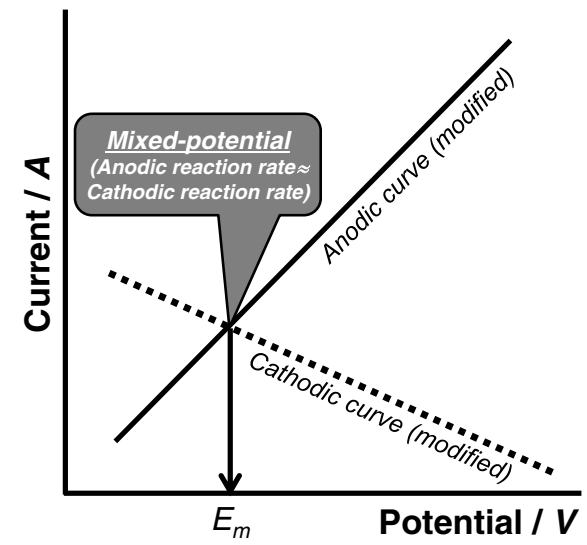

(b)

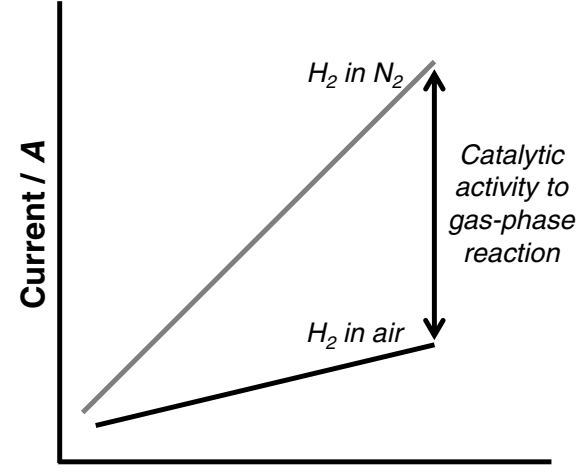

Potential / V

(c)

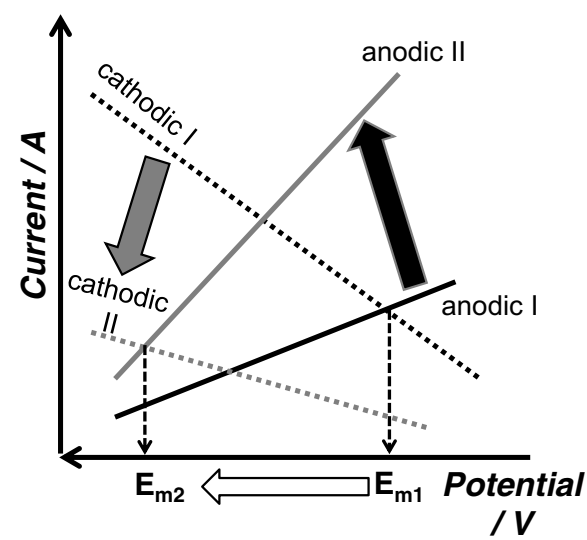

Fig. 5 a Schematic polarization curves for mixed-potential type sensor; b comparison of anodic polarization curves in air and in $\mathrm{N}_{2}$; and c elucidation of an increase in gas sensitivity by using shifts of polarization curves

catalytic activity to cathodic reaction (3) of $\mathrm{O}_{2}$, and a decrease in the heterogeneous catalysis to the gas-phase reaction (4) of the target gas $\left(\mathrm{H}_{2}\right)$. Figure $5 \mathrm{c}$ shows an example of the method how higher $\mathrm{H}_{2}$ sensitivity can be attained by increasing anodic current of $\mathrm{H}_{2}$ as well as decreasing cathodic current of $\mathrm{O}_{2}$. Higher anodic current of $\mathrm{H}_{2}$ is captured either by reducing the catalytic activity to the gas-phase reaction (4) which will increase the reactivity to anodic reaction (2) of $\mathrm{H}_{2}$ or by employing an SE material that specifically has high catalytic activity toward anodic reaction (2) of $\mathrm{H}_{2}$. Lower cathodic current of $\mathrm{O}_{2}$ can be obtained by employing an SE material that also has low catalytic activity to cathodic reaction (3) of $\mathrm{O}_{2}$. As a result, an increase in the anodic current of $\mathrm{H}_{2}$ and a decrease in cathodic current of $\mathrm{O}_{2}$ shift largely the mixedpotential to a more negative direction $\left(E_{m 1}\right.$ to $\left.E_{m 2}\right)$ (Fig. 5 c), which is experimentally observed to possess higher gas sensitivity.

Alternative approach was proposed by Wachsman et al., namely "Differential Electrode Equilibria," which particularly elucidates the sensing behavior of the sensor using semiconducting oxide SE [87-89]. This theory also takes gas-phase reaction and electrochemical reaction into account, when explaining the sensing mechanism. However, the "Differential Electrode Equlibria" theory strongly believes that the gas adsorption phenomena that occurs within semiconductor SE can govern the output sensing signal of the sensor. For example, in the case of a $p$-type semiconductor oxide (e.g., $\left.\mathrm{La}_{2} \mathrm{CuO}_{4}\right) \mathrm{SE}$ for $\mathrm{NO}$ detection, adsorbed $\mathrm{NO}$ on the surface of the $\mathrm{SE}$ particles facilitates the removal of electrons from the bulk of SE. As a result, the conductivity of the material is decreased, which may shift the Fermi level of the SE material, raising the positive potential change for NO detection [89], unlike the behavior of a normal mixed-potential type $\mathrm{NO}_{x}$ sensor.

Different approach in explaining the mechanism for nonNernstian behavior is based on the principle of the YSZ-based $\mathrm{O}_{2}$ sensor using an equilibrium potential, reported by Moseley and Tofield [35], Mcaleer et al. [41, 42], Li et al. [37], Tan and Tan [38], and Mori et al. [90,91]. In this case, the difference of $\mathrm{O}_{2}$ concentration between $\mathrm{SE}$ and RE produces the emf changes, according to Nernst equation for an oxygen concentration cell. Based on this principle, the change in $\mathrm{O}_{2}$ activity at $\mathrm{SE}$ caused by a sample gas exposure can generate the change in potential difference between SE and RE. For example, reducing gases remove and/or replace the adsorbed $\mathrm{O}_{2}$ molecules on SE, which decreases the effective activity of $\mathrm{O}_{2}$, and consequently changes the potential difference signal.

\section{CO sensor}

$\mathrm{CO}$ exists as a product of incomplete combustion process of fossil fuel or any burning appliances. Inhaling $\mathrm{CO}$ would lead to a reaction of $\mathrm{CO}$ with the iron part of the hemoglobin to form a complex compound (carboxyhemoglobin, $\mathrm{COHb}$ ). This complex compound may reduce the oxygen carrying capacity of our blood. Depending on the inhaled CO concentration, $\mathrm{CO}$ poisoning would trigger various detrimental effects to our health starting from a headache to a very fatal repercussion like death. Since CO is an odorless and colorless gas, the presence of $\mathrm{CO}$ sensor is pivotal in preventing $\mathrm{CO}$ poisoning.

As an SE material, noble metal (Pt or Mo) and metal alloys (Pt-Au or Pt-Cu) were initially used and examined for $\mathrm{CO}$ 
sensing, since they generated significant emf when exposed to $\mathrm{CO}$ diluted with air $[33,36,39,40,92]$. Okamoto et al. postulated that the adsorption of both $\mathrm{CO}$ and $\mathrm{O}_{2}$ on the surface of Pt-SE is believed to be responsible for the $\mathrm{CO}$ sensing signal generation [33]. Then, it was reported that the utilization of catalyst layer, $\mathrm{Pt} / \mathrm{Al}_{2} \mathrm{O}_{3}$ [33], $\mathrm{CuO}-\mathrm{ZnO}$ [37], or $\mathrm{SnO}_{2}$ [93] coated on Pt-SE could improve the CO sensitivity. Figure 6a shows the schematic structure of the sensor using $\mathrm{Al}_{2} \mathrm{O}_{3}(+\mathrm{Pt})$ catalyst coated on Pt-SE, while Fig. $6 \mathrm{~b}$ shows the dependence of sensitivity of this sensor on $\mathrm{CO}$ concentration at $300{ }^{\circ} \mathrm{C}$ [33].

Noble metals remain considered as a commendable choice for an SE material. As a recent example, Plashnitsa et al. have reported the performance of mixed-potential type YSZ-based CO sensor using Rh-SE, together with the corresponding SEM images of the Rh particles (Fig. 7) [94]. The cross sensitivity of this $\mathrm{CO}$ sensor using submicron Rh particles SE and Pt-RE has confirmed the capability of the sensor to generate a relatively sensitive response to $\mathrm{CO}$ at temperature as high as $700{ }^{\circ} \mathrm{C}$ (Fig. 7a) [94]. This sensor could detect CO as low as $50 \mathrm{ppm}$ with acceptable response and recovery speed. The unique shape, size, and orientation of Rh particle are believed to ensure the preferential sites for $\mathrm{CO}$ adsorption and migration toward the triple phase boundary (TPB).

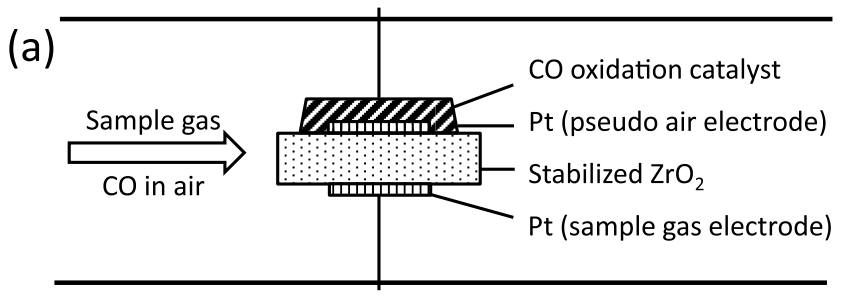

(b)

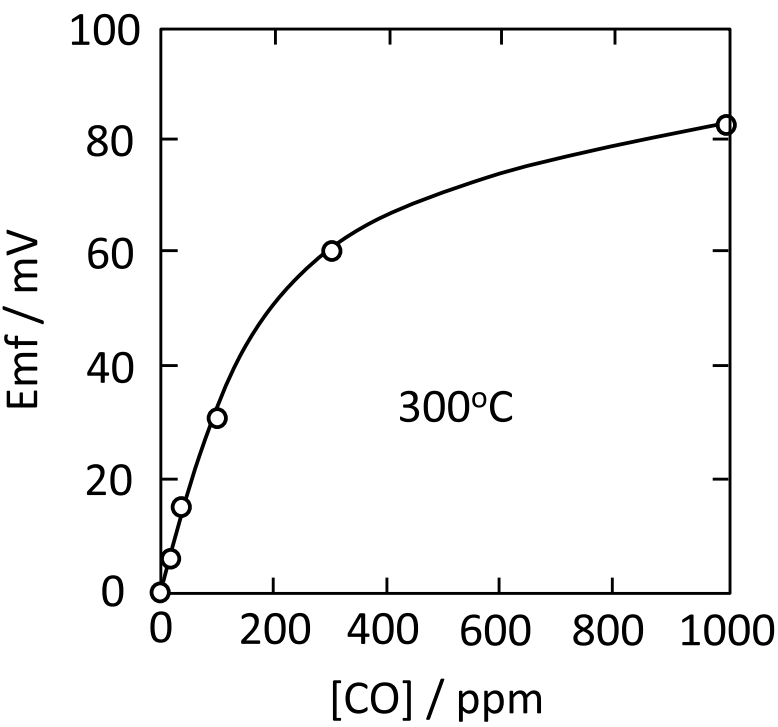

Fig. 6 a Schematic structure and $\mathbf{b}$ dependence of the sensitivity on $\mathrm{CO}$ concentration, for the $\mathrm{Al}_{2} \mathrm{O}_{3}(+\mathrm{Pt}) / \mathrm{Pt}|\mathrm{YSZ}| \mathrm{Pt}$ sensor. [Reproduced from [33], Copyright 1980, with permission from Elsevier]

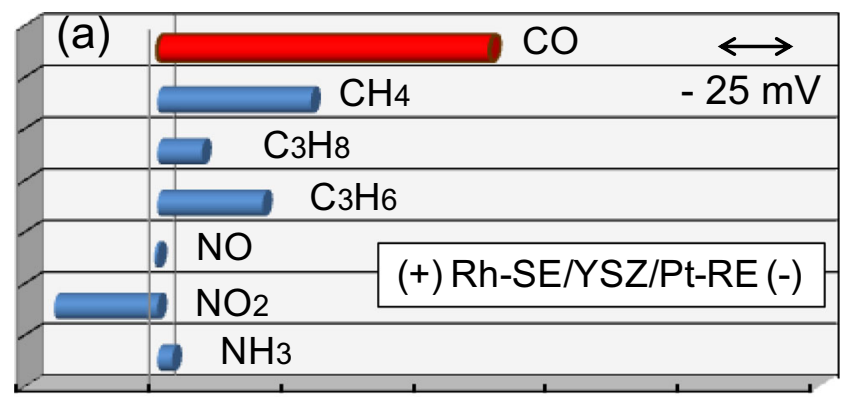

(b)
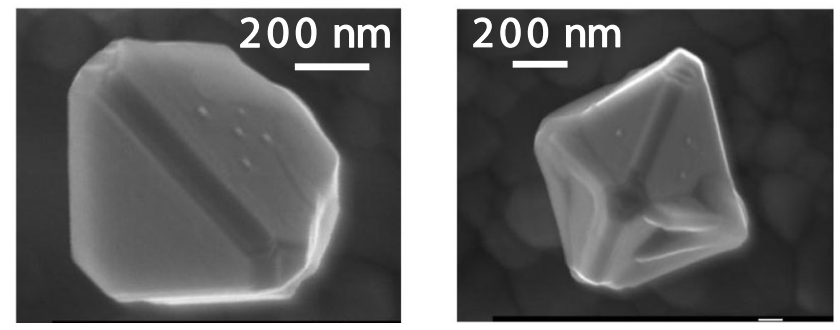

Fig. 7 a Cross sensitivity of the YSZ-based sensor using Rh-SE and Pt$\mathrm{RE}$; and $\mathbf{b}$ SEM images of submicron Rh particles formed on YSZ surface. [Reproduced from [94], Copyright 2011, with permission from Elsevier]

Other than submicron-sized metal particles, nano-sized particle is also used as an SE material. Nano-sized particle is believed to provide much higher active surface area, compared with submicron-sized particle. However, high surface area feature in a nano-sized material is not always beneficial when it is employed as SE. For example, the sensor using $\mathrm{Au}$ with higher apparent surface area is reported to exhibit lower CO sensitivity, when compared with the sensor using Au with lower apparent surface area. Interestingly, the lower apparent surface area Au that would naturally have smaller number of active reaction sites at TPB was confirmed to also have lower catalytic activity to the gas-phase reaction of CO. This, in turn, resulting in greater number of gaseous $\mathrm{CO}$ species capable of reaching TPB; hence, greater sensitivity was generated; as reported by Striker et al. [95]. In this case, the utilization of sensing material having lower apparent surface area can be more advantageous for further $\mathrm{CO}$ sensor development.

Efforts in finding inexpensive SE materials having high $\mathrm{CO}$ sensitivity have led to the utilization of different types of oxides as an SE material in different sensor configurations. Table 1 summarizes the typical examples of the usage of various oxides as an SE material in mixed-potential type $\mathrm{CO}$ sensors. One of the oxides that had attracted a lot of interests is perovskite-type oxide. Since the first report by Sorita and Kawano [49], perovskite-type oxides have been proposed to be used as an SE material to increase the CO sensitivity by several research groups [50, 85, 96-99]. The recent successful method to enhance $\mathrm{CO}$ sensitivity reported so far is the utilization of a metal catalyst such as Au together with an oxideSE [100-102]. 
Table 1 Comparison of sensing performance of the mixed-potential type zirconia-based CO sensors using each of various oxides as an SE material

\begin{tabular}{|c|c|c|c|c|c|}
\hline $\begin{array}{l}\text { Sensor structure } \\
\text { SE | YSZ | RE }\end{array}$ & $\begin{array}{l}\text { Sensor } \\
\text { configuration }\end{array}$ & $\begin{array}{l}\text { Operating } \\
\text { temp. }\left({ }^{\circ} \mathrm{C}\right)\end{array}$ & $\begin{array}{l}\text { Detection range } \\
(\mathrm{ppm})\end{array}$ & Year & Ref. \\
\hline $\mathrm{Pt}|\mathrm{CSZ}| \mathrm{Pt}$ & Tubular & 600 & $0-15,000$ & 1978 & {$[32]$} \\
\hline $\mathrm{Al}_{2} \mathrm{O}_{3}(+\mathrm{Pt}) / \mathrm{Pt}|\mathrm{YSZ}| \mathrm{Pt}$ & Separated & 350 & $0-1,000$ & 1980 & {$[33]$} \\
\hline $\mathrm{Au} / \mathrm{Ba}_{0.9} \mathrm{Gd}_{0.1} \mathrm{SnO}_{3}|\mathrm{YSZ}| \mathrm{Pt}$ & Planar & 300 & $100-1,000$ & 1989 & {$[41]$} \\
\hline $\mathrm{Pt}-\mathrm{Au}|\mathrm{YSZ}| \mathrm{Pt}$ & Tubular & 550 & $0-10,000$ & 1993 & {$[36]$} \\
\hline $\mathrm{CuO}-\mathrm{ZnO} / \mathrm{Pt}|\mathrm{YSZ}| \mathrm{Pt}$ & Planar & 450 & $150-10,000$ & 1993 & {$[37]$} \\
\hline $\mathrm{RuO}_{2}|\mathrm{YSZ}| \mathrm{Pt}$ & Separated $^{\mathrm{a}}$ & $400-600$ & $10-800$ & 1994 & [39] \\
\hline $\mathrm{SnO}_{2}|\mathrm{YSZ}| \mathrm{CdO}$ & Combined & 600 & $20-200$ & 1998 & {$[84]$} \\
\hline $\mathrm{Au} / \mathrm{LaCoO}_{3}|\mathrm{YSZ}| \mathrm{Au}$ & Planar & 600 & $243-1,800$ & 2000 & {$[97]$} \\
\hline $\mathrm{LaMnO}_{3} \mid$ YSZ $\mid \mathrm{Y}_{0.17} \mathrm{~Tb}_{0.17} \mathrm{Zr}_{0.66} \mathrm{O}_{2-x}$ & Planar & 600 & $29-310$ & 2000 & {$[85]$} \\
\hline $\mathrm{LaMnO}_{3}|\mathrm{YSZ}| \mathrm{Y}_{0.16} \mathrm{~Tb}_{0.30} \mathrm{Zr}_{054} \mathrm{O}_{2-x}$ & Planar & 600 & $29-500$ & 2002 & [96] \\
\hline $\mathrm{Au}-\mathrm{Co}_{3} \mathrm{O}_{4}|\mathrm{YSZ}| \mathrm{Pt}$ & Planar & 300 & 1,000 & 2003 & [100] \\
\hline $\mathrm{Nb}_{2} \mathrm{O}_{5} / \mathrm{Au}|\mathrm{YSZ}| \mathrm{Pt}$ & Planar & 450 & $200-1,000$ & 2008 & [87] \\
\hline LSM $|\mathrm{YSZ}| \mathrm{Au}$ & Planar & 530 & $10-200$ & 2008 & [98] \\
\hline $\mathrm{TiO}_{2}-\mathrm{Y}_{2} \mathrm{O}_{3}-\mathrm{Pd}|\mathrm{YSZ}| \mathrm{TiO}_{2}$ & Planar & 500 & $16-800$ & 2010 & [176] \\
\hline $\mathrm{Rh}|\mathrm{YSZ}| \mathrm{Pt}$ & Planar & 700 & $50-400$ & 2011 & {$[94]$} \\
\hline $\mathrm{ZnCr}_{2} \mathrm{O}_{4}(+\mathrm{Au})|\mathrm{YSZ}| \mathrm{ZnCr}_{2} \mathrm{O}_{4}$ & Combined & 550 & $20-800$ & 2011 & [102] \\
\hline $\mathrm{Nb}_{2} \mathrm{O}_{5}(+\mathrm{Au})|\mathrm{YSZ}| \mathrm{NiO}(+\mathrm{Au})$ & Combined & 450 & $10-400$ & 2011 & [101] \\
\hline $\mathrm{Au}(+\mathrm{YSZ})|\mathrm{YSZ}| \mathrm{Pt}$ & Planar & 500 & $10-300$ & 2013 & {$[95]$} \\
\hline $\mathrm{Zn}_{2} \mathrm{SnO}_{4}\left(+\mathrm{SnO}_{2}\right)|\mathrm{YSZ}| \mathrm{Pt}$ & Planar & 600 & $60-1,140$ & 2013 & [177] \\
\hline
\end{tabular}

LSM strontium-doped lanthanum manganite

${ }^{a}$ Separated configuration means SE and RE are located in separated chamber and exposed to different atmosphere, where SE in sensing chamber will be exposed to testing gas and RE in reference chamber will be exposed to reference gas

Elucidation of the Au role in enhancing $\mathrm{CO}$ sensitivity has been attempted by using the sensor attached with $\mathrm{Nb}_{2} \mathrm{O}_{5^{-}}$ based $\mathrm{SE}$ [101] or $\mathrm{ZnCr}_{2} \mathrm{O}_{4}$-based SE [102]. Based on the polarization curve measurements, the presence of $\mathrm{Au}$ at TPB was confirmed to increase the catalytic activity particularly to the anodic reaction of $\mathrm{CO}$. In the case of the sensor using $\mathrm{ZnCr}_{2} \mathrm{O}_{4}$-SE, the presence of $\mathrm{Au}$ in SE only slightly affects the catalytic activity to the gas-phase oxidation reaction of $\mathrm{CO}$. Thus, the high CO sensitivity is believed to be predominantly promoted by the increase in the catalytic activity to the anodic reaction of $\mathrm{CO}$ [102]. Unfortunately, the high response to $\mathrm{CO}$ that was brought by the addition of $\mathrm{Au}$ into the oxide SE was often followed also by high responses to other gases (poor selectivity to CO) [101-103].

Up to now, the selectivity issue has been most effectively overcome by using a combined-type configuration, as initially proven by Miura et al. [84]. In a combined-type configuration, a CO-sensitive material is paired with a $\mathrm{CE}$ that is sensitive and selective to the interfering gases, especially HCs [84, 101, 102]. Figure 8a shows the results reported by Fujio et al. on the combined-type sensor using a tubular YSZ attached with $\mathrm{ZnCr}_{2} \mathrm{O}_{4}(+\mathrm{Au})$ as $\mathrm{SE}$ and $\mathrm{ZnCr}_{2} \mathrm{O}_{4}$ as $\mathrm{CE}$ [102]. The unwanted $\mathrm{C}_{3} \mathrm{H}_{8}$ response that is initially observed for the sensor using $\mathrm{ZnCr}_{2} \mathrm{O}_{4}(+\mathrm{Au})-\mathrm{SE}$ can be diminished by pairing it with $\mathrm{ZnCr}_{2} \mathrm{O}_{4}-\mathrm{CE}$ that is sensitive and selective to $\mathrm{C}_{3} \mathrm{H}_{8}$. Then, only $\mathrm{CO}$ response can remain high. Figure $8 \mathrm{~b}$ depicts the improved $\mathrm{CO}$ selectivity under such a combined configuration [102]. Another strategy in obtaining the selective CO detection was proposed by employing an oxidation catalyst formed on the top of SE to reduce or oxidize the unwanted gas species. For example, the oxidation catalyst material such as Pt- $\mathrm{Al}_{2} \mathrm{O}_{3}$ proved to be capable of suppressing the interfering $\mathrm{H}_{2}$ sensitivity [50, 92, 104].

The most important characteristic of practical gas sensors is a long-term stability. In the group of CO-sensitive materials reported to date, there are only a few that confirmed to be able to retain a stable performance for a long-term operation. Among those $\mathrm{CO}$ sensors, the sensor, $\mathrm{Y}_{0.16} \mathrm{~Tb}_{0.30} \mathrm{Zr}_{0.54} \mathrm{O}_{2-x}|\mathrm{YSZ}| \mathrm{LaMnO}_{3}$, reported by Brosha et al., exhibited stable $\mathrm{CO}$ signal throughout 1,400 h (about 58 days) of continuous operation (Fig. 9) [96]. Another excellent stability was also reported by Mochizuki et al. in the sensor, Pt- $\mathrm{Al}_{2} \mathrm{O}_{3}|\mathrm{YSZ}| \mathrm{Pt}$, which was capable of showing the stable $\mathrm{CO}$ response for nearly $4,000 \mathrm{~h}$ (about 167 days) of operation [104].

\section{Hydrocarbon sensor}

Table 2 represents typical examples of the recently reported YSZ-based HC sensors. There are several papers regarding 
(a)

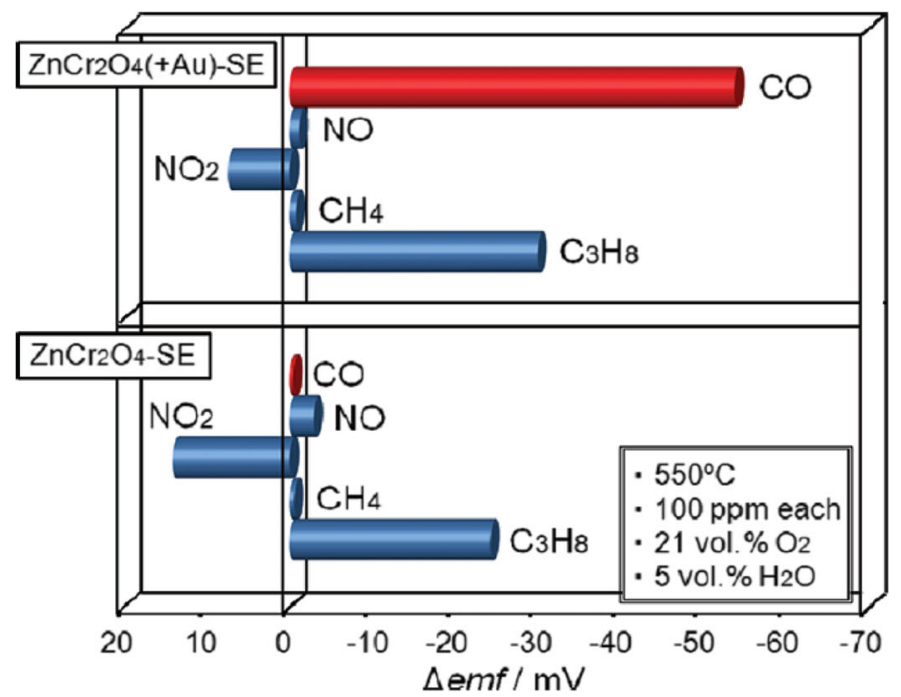

(b)

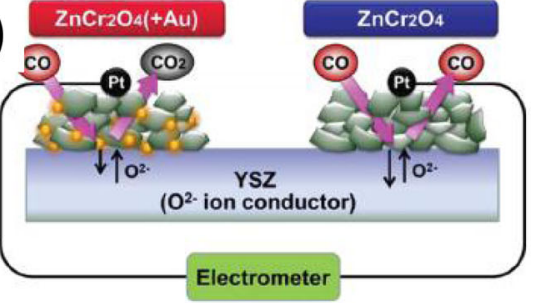

(c)

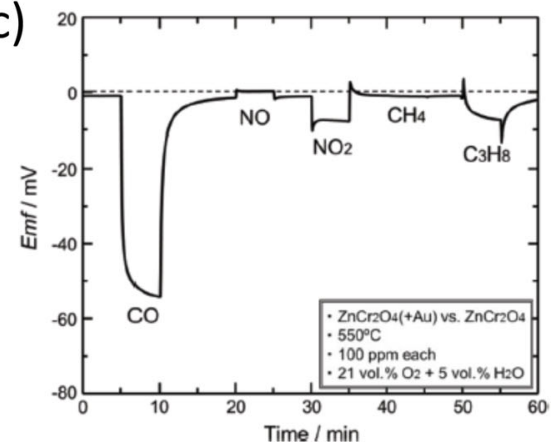

Fig. 8 a Cross-sensitivity comparison of the sensors using each of $\mathrm{ZnCr}_{2} \mathrm{O}_{4}(+\mathrm{Au})-\mathrm{SE}$ and $\mathrm{ZnCr}_{2} \mathrm{O}_{4}$-SE; $\mathbf{b}$ schematics view of the sensor construction; and $\mathbf{c}$ the response transient to various gases, for the developed combined-type YSZ-based sensor. [Reproduced from [102], Copyright 2011, with permission from the American Chemical Society]

oxidation (or decomposition) of HCs within a SE layer of the sensor, the actual concentration of $\mathrm{HCs}$ at the SE/YSZ interface will be decreased, resulting in a reduction of HC sensitivity. In the similar manner, Müller et al. reported that the doping of $\mathrm{Sr}$ to A site of $\mathrm{LaCr}_{1-y} \mathrm{Ga}_{y} \mathrm{O}_{3-\delta}$ decreased the gas-phase activity as well as the HC sensitivity [107]. However, the reduction in a gas-phase activity of an SE material normally causes the decrease in its electrochemical activity for the reaction involving a target gas. Since these two activities reversely militate to sensitivity each other, the balancing of each activity is the key for managing high HC sensitivity of the sensor. The YSZ-based sensors mentioned above were able to detect HCs in parts per million levels, which are useful for automobile applications. However, Mori et al. [91, 110] and Sato et al. [111, 112] reported that the YSZ-based sensors operating at low temperatures could detect very low concentration at parts per billion levels of HCs including volatile organic compounds (VOCs) such as toluene and xylene in atmospheric environments.

Both the gas-phase catalytic activities and the electrochemical reactions are the main factors which govern HCs sensitivity. In addition, selectivity to HCs is another sensor's characteristic controlled by these two factors. For example, Ueda et al. reported that the operation of the YSZ-based sensor using $\mathrm{In}_{2} \mathrm{O}_{3}$-SE at rather high temperature of $790{ }^{\circ} \mathrm{C}$ produced a remarkable improvement in $\mathrm{CH}_{4}$ selectivity [113]. This sensor utilized a specific property of $\mathrm{CH}_{4}$ which has a lower gas-phase reactivity compared with other gases even at high temperatures, resulted in the suppression of the $\mathrm{CH}_{4}$ oxidation within the SE layer and managing the high $\mathrm{CH}_{4}$ sensitivity compared with other gases at around $790{ }^{\circ} \mathrm{C}$, as depicted in 
Table 2 Typical examples of mixed-potential type YSZ-based HCs sensors

\begin{tabular}{|c|c|c|c|c|c|}
\hline $\begin{array}{l}\text { Sensor structure } \\
\text { SE | YSZ | RE }\end{array}$ & $\begin{array}{l}\text { Sensor } \\
\text { configuration }\end{array}$ & $\begin{array}{l}\text { Operating } \\
\text { temp. }\left({ }^{\circ} \mathrm{C}\right)\end{array}$ & $\begin{array}{l}\text { Detection range } \\
(\mathrm{ppm})\end{array}$ & Year & Ref. \\
\hline $\mathrm{Au}|\mathrm{YSZ}| \mathrm{Pt}$ & Tubular & 700 & $500-6,000$ & 1996 & [178] \\
\hline $\mathrm{Au}|\mathrm{YSZ}| \mathrm{Pt}$ & Separated & 600 & $100-500$ & 1998 & [118] \\
\hline $\mathrm{Au}\left(+\mathrm{Ta}_{2} \mathrm{O}_{5}\right)|\mathrm{YSZ}| \mathrm{Pt}$ & Separated & $600-750$ & $100-500$ & 1999 & [105] \\
\hline $\mathrm{In}_{2} \mathrm{O}_{3}\left(+\mathrm{MnO}_{2}\right)|\mathrm{YSZ}| \mathrm{Pt}$ & Separated & 600 & $100-500$ & 1999 & [115] \\
\hline $\mathrm{CdO}|\mathrm{YSZ}| \mathrm{Pt}$ & Tubular & 600 & $50-800$ & 2000 & [119] \\
\hline $\mathrm{Pt}\left(+\mathrm{SrCe}_{0.95} \mathrm{Yb}_{0.05} \mathrm{O}_{3-\delta}\right)|\mathrm{YSZ}| \mathrm{Pt}$ & Separated & 600 & $200-1,000$ & 2001 & {$[51]$} \\
\hline $\mathrm{Au}-\mathrm{Ga}_{2} \mathrm{O}_{3}|\mathrm{YSZ}| \mathrm{Pt}$ & Tubular & 700 & $500-8,000$ & 2001 & [106] \\
\hline $\mathrm{Nb}_{2} \mathrm{O}_{5}-\mathrm{Au}|\mathrm{YSZ}| \mathrm{Pt}$ & Tubular & 700 & $500-8,000$ & 2002 & {$[14]$} \\
\hline $\mathrm{La}_{0.95} \mathrm{Sr}_{0.02} \mathrm{Cr}_{1-y} \mathrm{Ga}_{y} \mathrm{O}_{3-\delta}|\mathrm{YSZ}| \mathrm{Pt}$ & Tubular & 700 & $500-8,000$ & 2002 & [107] \\
\hline $\mathrm{La}_{0.8} \mathrm{Sr}_{0.2} \mathrm{CrO}_{3}|\mathrm{YSZ}| \mathrm{Pt}$ & Planar & 550 & $50-500$ & 2003 & [179] \\
\hline $\mathrm{Au}-\mathrm{Nb}_{2} \mathrm{O}_{5}|\mathrm{YSZ}| \mathrm{Pt}$ & Tubular & 700 & 4,000 & 2004 & [108] \\
\hline $\mathrm{Pt}|\mathrm{YSZ}| \mathrm{Pr}_{6} \mathrm{O}_{11}$ & Combined & 800 & $100-500$ & 2005 & [116] \\
\hline $\mathrm{Nb}_{2} \mathrm{O}_{5}|\mathrm{YSZ}| \mathrm{Pt}$ & Planar & 700 & $200-1,000$ & 2008 & [120] \\
\hline $\mathrm{In}_{2} \mathrm{O}_{3}|\mathrm{YSZ}| \mathrm{Pt}$ & Tubular & 790 & 400 & 2008 & [113] \\
\hline $\mathrm{In}_{2} \mathrm{O}_{3}(+\mathrm{YSZ}+$ nano-Pt $)|\mathrm{YSZ}| \mathrm{Pt}$ & Tubular & 450 & $0.01-0.20$ & 2009 & [114] \\
\hline Nano-Au $\mid$ YSZ | Pt & Planar & 550 & $50-400$ & 2009 & [121] \\
\hline $\mathrm{Pt}|\mathrm{YSZ}| \mathrm{Pt}$ & Tubular & $400-500$ & $0.5-10$ & 2009 & [110] \\
\hline $\mathrm{NiO}(+\mathrm{Au})|\mathrm{YSZ}| \mathrm{Pt}$ & Planar & 600 & $10-400$ & 2010 & [117] \\
\hline $\mathrm{Nb}_{2} \mathrm{O}_{5}-\mathrm{Ta}_{2} \mathrm{O}_{5}|\mathrm{YSZ}| \mathrm{Pt}$ & Planar & 700 & $200-1,000$ & 2010 & [122] \\
\hline $\mathrm{Au} / \mathrm{Pt}|\mathrm{YSZ}| \mathrm{Pt}$ & Tubular & $400-500$ & $0.5-10$ & 2010 & [91] \\
\hline $\mathrm{NiO}|\mathrm{YSZ}| \mathrm{Pt}$ & Tubular & 450 & $0.01-0.3$ & 2011 & [111] \\
\hline $\mathrm{ZnCr}_{2} \mathrm{O}_{4} / \mathrm{YSZ}|\mathrm{YSZ}| \mathrm{Pt}$ & Tubular & 550 & $100-2,000(\mathrm{ppmC})$ & 2011 & {$[58]$} \\
\hline $\mathrm{In}_{2} \mathrm{O}_{3}(+\mathrm{YSZ}+$ nano-Pt)/YSZ | YSZ | YSZ/Pt & Rod & 450 & $0.02-0.6$ & 2012 & [112] \\
\hline $\mathrm{La}_{0.9} \mathrm{Sr}_{0.1} \mathrm{CrO}_{3}|\mathrm{YSZ}| \mathrm{Pt}$ & Planar & 500 & $25-100$ & 2013 & [123] \\
\hline $\mathrm{SnO}_{2} /$ nano- $-\mathrm{Al}_{2} \mathrm{O}_{3} / \mathrm{NiO}\left(+\mathrm{Al}_{2} \mathrm{O}_{3}\right)|\mathrm{YSZ}| \mathrm{Pt}$ & Tubular & 500 & $25-100$ & 2013 & {$[77]$} \\
\hline
\end{tabular}

Fig. 10. The utilization of an additional catalyst was also an effective approach to control the gas-phase activity. Sato et al. reported that the lamination of a $\mathrm{SnO}_{2}$ catalyst layer on NiOSE was able to facilitate the oxidation of ethanol (interfering gas) and, as a result, the selectivity to toluene (target gas) was substantially improved [77]. On the same basis, Wama et al. reported that the addition of $\mathrm{Pt}$ nanoparticles to $\mathrm{In}_{2} \mathrm{O}_{3}-\mathrm{SE}$ ensured the decomposition of interfering gases (such as $\mathrm{H}_{2}$ and $\mathrm{CO}$ ), which contributed to attain the high $\mathrm{C}_{3} \mathrm{H}_{6}$ selectivity at parts per billion levels [114]. However, the addition of a second component to the SE materials can also change its electrochemical catalytic activity. Hibino et al. reported that the addition of $0.1 \mathrm{wt} \% \mathrm{MnO}_{2}$ to $\mathrm{In}_{2} \mathrm{O}_{3}$-SE decreased the electrochemical catalytic activity of SE toward $\mathrm{H}_{2}$ and $\mathrm{CO}$, while maintaining the high catalytic activity to $\mathrm{C}_{3} \mathrm{H}_{6}$ [115].

Not only SE but also RE can contribute to improve the HCs selectivity. For instance, RE in the planar sensor geometry frequently ingenerates a mixed potential, since RE is exposed to the sample gases, as mentioned in the previous section. Thus, the decrease in HCs sensitivity depends on appropriate selection of the RE material and its operating conditions. Figure 11 displays that the combination of Pt-SE and $\mathrm{Pr}_{6} \mathrm{O}_{11}-\mathrm{RE}$ can also enhance the selectivity to $\mathrm{C}_{3} \mathrm{H}_{8}$, especially at

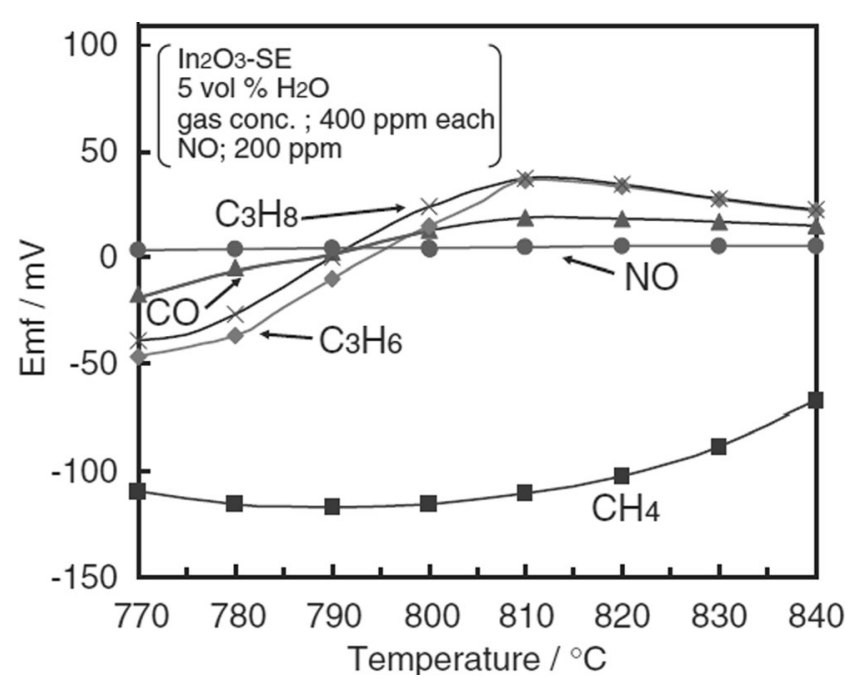

Fig. 10 Dependence of emf value to various gases on operational temperature for the YSZ-based sensor using $\mathrm{In}_{2} \mathrm{O}_{3}$-SE under humidified condition (5 vol $\left.\% \mathrm{H}_{2} \mathrm{O}\right)$. [Reproduced from [113], Copyright 2008, with permission from The Chemical Society of Japan] 
Fig. 11 Comparison of sensitivity to various gases for the YSZ-based sensor using Pt and $\mathrm{Pr}_{6} \mathrm{O}_{11}$ electrodes operated at a $750{ }^{\circ} \mathrm{C}$ and b $800^{\circ} \mathrm{C}$

[Reproduced from [116], Copyright 2005, with permission from Elsevier] (a) $750^{\circ} \mathrm{C}$

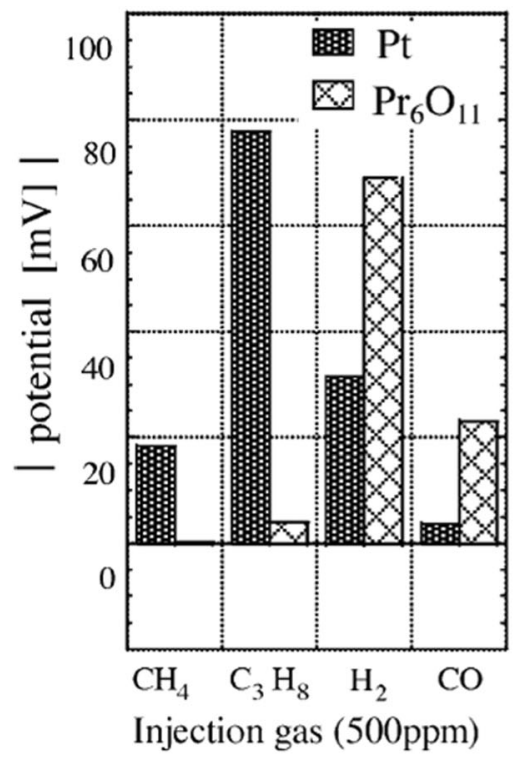

(b) $800^{\circ} \mathrm{C}$

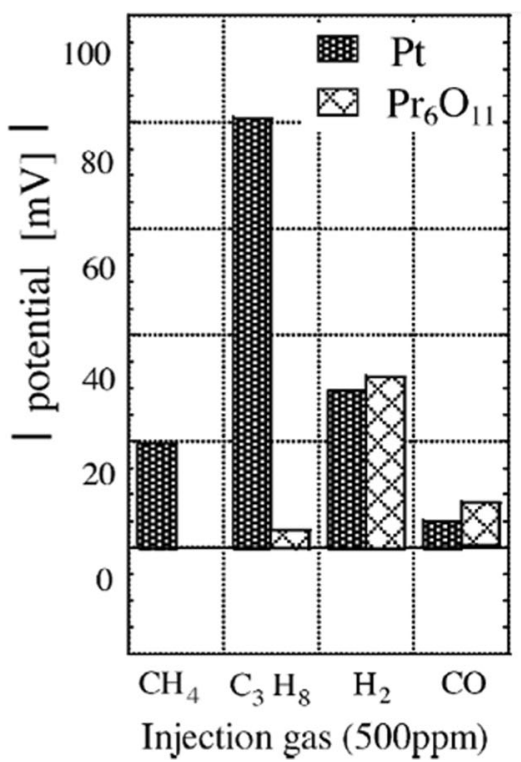

$800{ }^{\circ} \mathrm{C}$, by cancelling out the mixed potentials to $\mathrm{H}_{2}$ and $\mathrm{CO}$ between two electrodes, as reported by Inaba et al. [116].

In order to bring a sensor closer to commercial reality, sensing characteristics are needed to be stable for long term. In general, the poor stability is due to the change in morphology of an SE layer and/or an SE/YSZ interface. This is usually caused by a long-term operation at high temperatures. However, there was an example when the SE was succeeded to be stabilized by applying several methodologies. For example, Wama et al. reported that the addition of YSZ particles impregnated into $\mathrm{In}_{2} \mathrm{O}_{3}$-SE suppressed the morphological change in the SE/YSZ interface, which was a key factor for SE stability [114]. In a similar manner, Fujio et al. reported that the intercalation of a layer consisted of YSZ particles located between $\mathrm{ZnCr}_{2} \mathrm{O}_{4}$-SE and a YSZ substrate provided good stability [58]. In this particular electrode geometry, the $\mathrm{ZnCr}_{2} \mathrm{O}_{4}$ particles near the SE/ YSZ interface were partially surrounded by YSZ particles in the YSZ layer. It appeared that this complex structure could suppress the change in the interfacial condition, compared with the case of the SE in which only $\mathrm{ZnCr}_{2} \mathrm{O}_{4}$ particles were directly attached to the YSZ substrate having a smooth surface. Most of the oxide-SEs mentioned above are relatively stable at high temperatures. However, other SE materials with a lower melting point such as Au need to be stabilized by using a different approach. Figure 12a, b represents SEM images of Au-SEs before and after the sensor operation for 57 days, as reported by Elumalai et al. [117]. It was observed that $\mathrm{Au}$ particles were agglomerated and formed monolithic-like layer after the long-term operation at high temperatures. This drastic change in the morphology caused the decrease in $\mathrm{C}_{3} \mathrm{H}_{6}$ sensitivity of the YSZ-based sensor attached with Au-SE. However, isolated $\mathrm{Au}$ particles appeared to be stabilized even after 2 months of operation by using $\mathrm{NiO}$ as an alternative base component of the $\mathrm{SE}(\mathrm{NiO}, 95 \mathrm{wt} \%$ and $\mathrm{Au}$, $5 \mathrm{wt} \%$ ), as presented in Fig. 12c, d [117]. As a result, the sensor has maintained good stability toward $\mathrm{C}_{3} \mathrm{H}_{6}$ sensing.

Various HCs are existing in most of engine exhausts and can basically be classified into three types: alkane (such as $\mathrm{C}_{2} \mathrm{H}_{6}, \mathrm{C}_{3} \mathrm{H}_{8}, \mathrm{C}_{4} \mathrm{H}_{10}$ ), alkene (such as $\mathrm{C}_{2} \mathrm{H}_{4}, \mathrm{C}_{3} \mathrm{H}_{6}, \mathrm{C}_{4} \mathrm{H}_{8}$ ), and alkyne (such as $\mathrm{C}_{2} \mathrm{H}_{2}, \mathrm{C}_{3} \mathrm{H}_{4}, \mathrm{C}_{4} \mathrm{H}_{6}$ ). In general, the HCs sensitivity has been reported to be enhanced with increasing carbon number within the same HCs group, as illustrated in Fig. 13 [51, 58, 105, 107, 108, 110, 112, 114-123]. Additionally, it was also reported by Hibino et al. that HCs sensitivity increased with the order of alkane, alkene, and alkyne in the case of same carbon number (Fig. 13) [105]. Since there are a plenty of HCs in different combinations existing in automobile exhausts, a HCs sensor detecting the mixture of all HCs as a total concentration has been considered as the most ideal one. In this regard, Fujio et al. found that the YSZ-based sensor using $\mathrm{ZnCr}_{2} \mathrm{O}_{4}$-SE can measure the concentrations of the HCs mixture consisting of $\mathrm{C}_{2} \mathrm{H}_{6}, \mathrm{C}_{3} \mathrm{H}_{6}$, and $1-\mathrm{C}_{4} \mathrm{H}_{8}$, even when the mixing ratio of these $\mathrm{HCs}$ was varied [58]. The realization of total HCs detection is due to the specific HCs sensing characteristics of the present sensor that the HCs sensitivity depends on the carbon number but was not affected by an unsaturation grade of carbon-carbon bond of HCs. For example, Fig. 14 
Fig. 12 Back-scattering SEM images of the surface of $\mathbf{a}, \mathbf{b} \mathrm{Au}-$ and $\mathbf{c}, \mathbf{d ~} \mathrm{NiO}(+5 \mathrm{wt} \% \mathrm{Au})$-SEs: $\mathbf{a}, \mathbf{c}$ are as-sintered SEs and $\mathbf{b}, \mathbf{d}$ are SEs after 57-day operation. [Reproduced from [117], Copyright 2009, with permission from Elsevier]
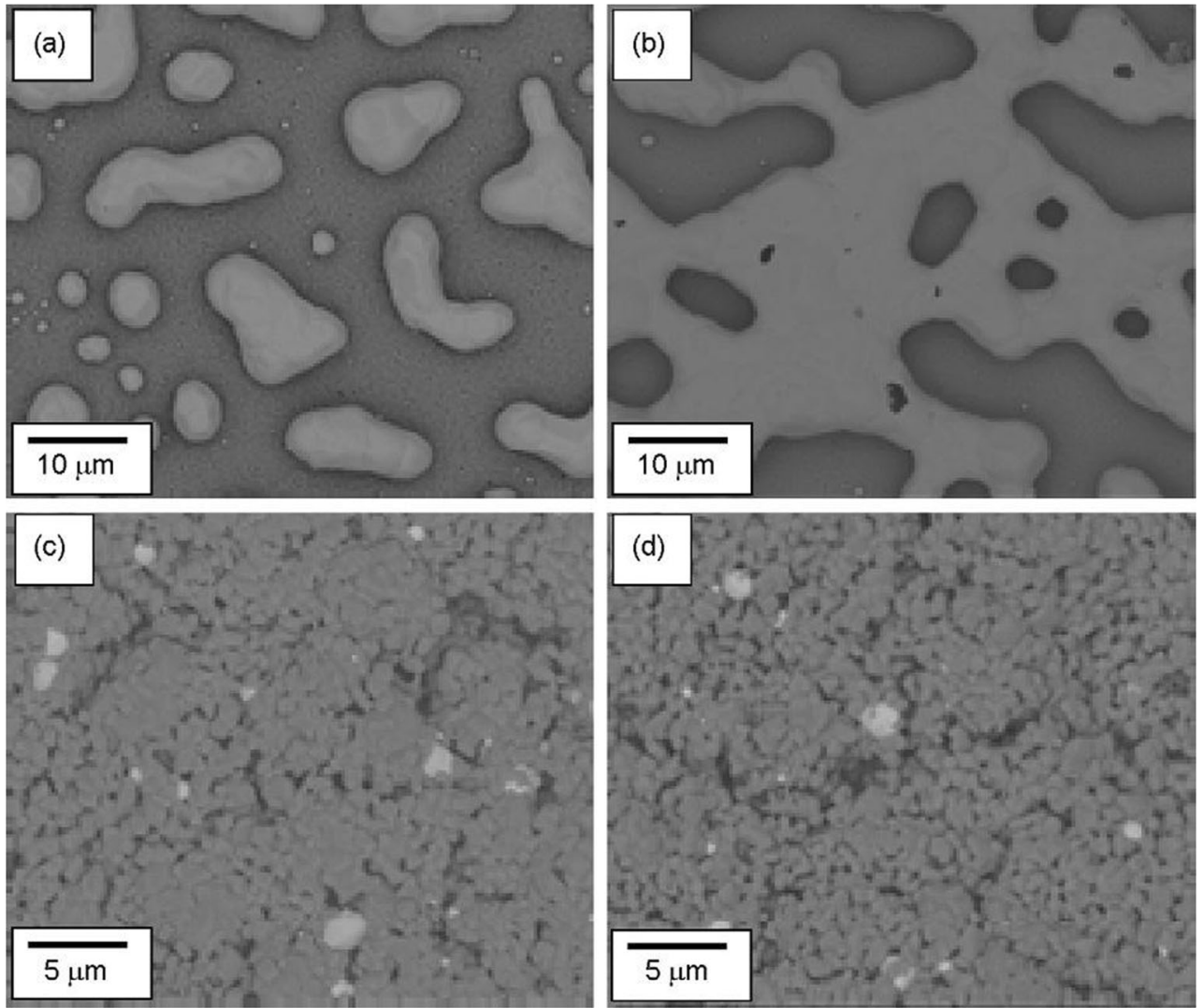

shows that the sensor using $\mathrm{ZnCr}_{2} \mathrm{O}_{4}$-SE gives practically same sensitivity to $\mathrm{C}_{3} \mathrm{H}_{8}, \mathrm{C}_{3} \mathrm{H}_{6}$, and $\mathrm{C}_{3} \mathrm{H}_{4}$ [58].

\section{NO $_{x}$ sensor}

The demand for accurate and precise in situ measurements of harmful pollutants such as $\mathrm{NO}_{x}\left(\mathrm{NO}\right.$ and $\left.\mathrm{NO}_{2}\right)$ gases emitted from automobiles and industrial processes is increasing for control of fuel combustion process and for monitoring air pollutants. The $\mathrm{NO}_{x}$ sensors based on YSZ as a solid electrolyte has been proven to be one of the most reliable devices

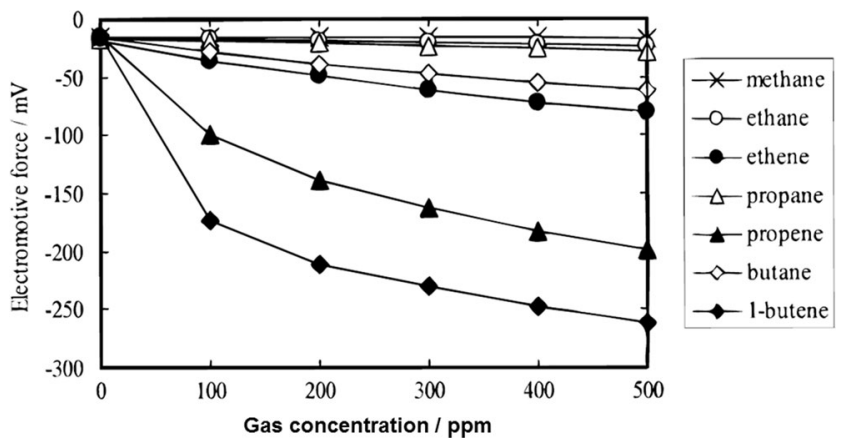

Fig. 13 Dependence of emf value on the concentration of various $\mathrm{HCs}$ for the YSZ-based sensor using $\mathrm{Au}\left(+\mathrm{Ta}_{2} \mathrm{O}_{5}\right)$-SE, operated at $600{ }^{\circ} \mathrm{C}$. [Reproduced from [105], Copyright 1999, with permission from The Electrochemical Society] enable to accomplish the desirable sensing properties [9, 29, $30,124]$. Over the last decade, important developments of the mixed-potential type YSZ-based $\mathrm{NO}_{x}$ gas sensors were

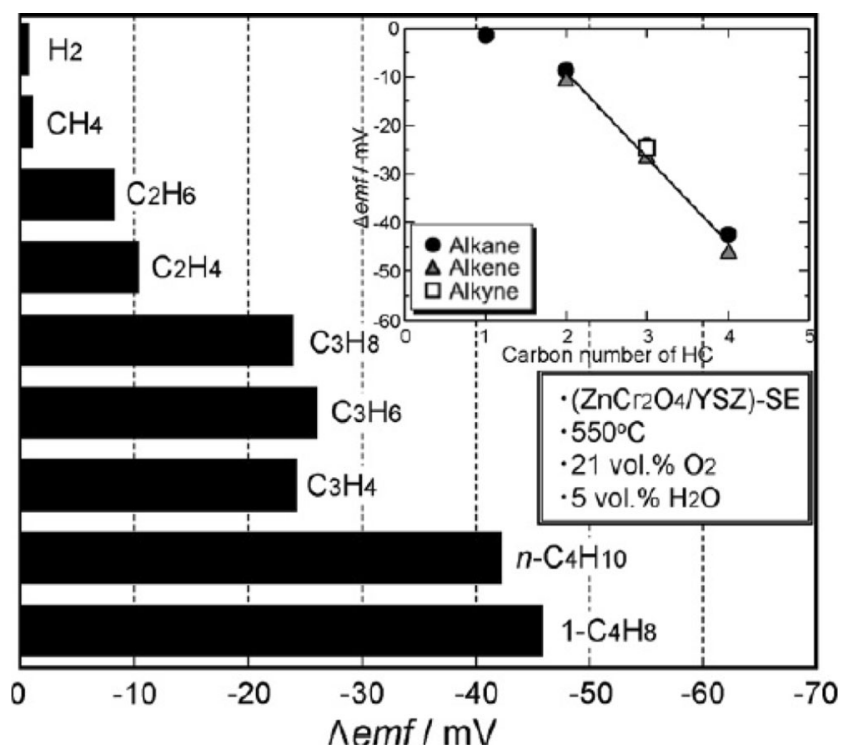

Fig. 14 Comparison of sensitivities to various $\mathrm{HCs}$ and $\mathrm{H}_{2}$ (100 ppm each) for the sensor using $\left(\mathrm{ZnCr}_{2} \mathrm{O}_{4} / \mathrm{YSZ}\right)$-SE, operated at $550{ }^{\circ} \mathrm{C}$ under humidified condition $\left(5 \mathrm{vol} \% \mathrm{H}_{2} \mathrm{O}\right)$. Inset, dependence of sensitivity on carbon number. [Reproduced from [58], Copyright 2011, with permission from Elsevier] 
adequately reported in many publications $[15,44,45,52,54$, 59, 76, 99, 125-153].

The mixed-potential type $\mathrm{NO}_{x}$ sensors can work on the following sensing mechanism [29, 30, 44]: when $\mathrm{NO}_{2}$ (or NO) coexists with $\mathrm{O}_{2}$ in exhausts, both anodic and cathodic reactions occur simultaneously at the SE/YSZ interface as follows, as first proposed by Miura et al. in 1996 [44, 45].

For $\mathrm{NO}_{2}$ :

(anodic) $\quad 2 \mathrm{O}^{2-} \rightarrow \mathrm{O}_{2}+4 \mathrm{e}^{-}$

(cathodic) $\quad 2 \mathrm{NO}_{2}+4 \mathrm{e}^{-} \rightarrow 2 \mathrm{NO}+2 \mathrm{O}^{2-}$

For NO:

(anodic) $2 \mathrm{NO}+2 \mathrm{O}^{2-} \rightarrow 2 \mathrm{NO}_{2}+4 \mathrm{e}^{-}$

(cathodic) $\mathrm{O}_{2}+4 \mathrm{e}^{-} \rightarrow 2 \mathrm{O}^{2-}$

When the rate of the anodic reaction (14) and (16) is equal to that of the cathodic reaction (15) and (17), respectively, the mixed-potential arises at SE. The emf responses to NO and $\mathrm{NO}_{2}$ for the YSZ-based $\mathrm{NO}_{x}$ sensor are opposite to each other: the emf value is positive toward $\mathrm{NO}_{2}$ and negative toward $\mathrm{NO}$. It should be noted that when the sample gas composition $(\mathrm{NO} /$ $\left.\mathrm{NO}_{2} / \mathrm{O}_{2}\right)$ is close to the equilibrium for the reaction $\left(2 \mathrm{NO}_{2}=\right.$ $2 \mathrm{NO}+\mathrm{O}_{2}$ ), almost no mixed potential is generated. In order to address this fact as well as to satisfy both high sensitivity and high selectivity of the mixed-potential type $\mathrm{NO}_{x}$ sensors, considerable attention has been paid for finding new SE materials and controlling their morphologies. Table 3 represents the summary of the mixed-potential type YSZ-based $\mathrm{NO}_{x}$ sensors which have been reported so far in literatures.

In the case of $\mathrm{NO}_{x}$ monitoring in vehicle exhausts, the sensor is required to operate within a temperature range of 550-900 ${ }^{\circ} \mathrm{C}$ because the engine's temperature sometimes reaches up to $900{ }^{\circ} \mathrm{C}$, especially during car acceleration. However, it was reported that the sensitivity of the mixedpotential type $\mathrm{NO}_{x}$ sensors decreases significantly at the working temperature over $600{ }^{\circ} \mathrm{C}$ [29]. Our research group has explored sensing capabilities of various SE materials toward both high sensitivity and high selectivity to $\mathrm{NO}_{x}$ at even higher temperatures. Figure 15 compares the output sensing signal to $400 \mathrm{ppm} \mathrm{NO}_{2}$ for the YSZ-based sensors using different oxide materials as SE. Among them, $\mathrm{NiO}$ was found to be one of the best suitable materials for $\mathrm{SE}$ of the $\mathrm{NO}_{x}$ sensor operated even at $850{ }^{\circ} \mathrm{C}[76,149]$.
The sensing characteristics of the mixed-potential type $\mathrm{NO}_{x}$ sensor is strongly dependent not only on the composition of SE material but also on its morphology including particle (grain) size, porosity, and thickness, due to the occurrence of gas-phase decomposition of $\mathrm{NO}_{2}$ to $\mathrm{NO}$, which generally occurs at high temperature during the diffusion process in the SE layer, as mentioned previously. This is relating to the change in catalytic activity of SE materials. Therefore, even for the same chemical composition of SE material, the $\mathrm{NO}_{x}$ sensing characteristics can be quite different if the SE materials prepared by the different synthesis methods and different sintering temperatures $[151,152]$. For example, Plashnitsa et al. reported that $\mathrm{NiO}$ nanoparticles were utilized for fabrication of NiO-SE, which were evaluated in the planar $\mathrm{NO}_{2}$ sensor $[121,153]$. The $\mathrm{NiO}$ nanoparticles having about $3 \mathrm{~nm}$ diameter were prepared for SE material precursor by means of ball-milling of the parent $\mathrm{Ni}(\mathrm{OH})_{2}$ powder derived from a sol-gel method. Subsequently, an $\mathrm{NiO}$ layer was fabricated on the YSZ plate, followed by sintering at $800,1,100$, and $1,400{ }^{\circ} \mathrm{C}$ for $2 \mathrm{~h}$ in air. Figure 16 shows the surface morphologies of the $\mathrm{NiO}$ nanoparticle sintered at each temperature and their corresponding crosssensitivities to the various gases at $800{ }^{\circ} \mathrm{C}$. Each NiO-SE produced high $\mathrm{NO}_{2}$ sensitivity even at such a high operating temperature regardless the difference in sintering temperature, whereas the high $\mathrm{NO}_{2}$ selectivity was only attained by the SE sintered at $1,100{ }^{\circ} \mathrm{C}$ [153].

It has been also reported that the use of composite materials as $\mathrm{SE}$ is one of the most effective techniques for improvement of the sensor characteristics. For example, Xiong and Kale reported that the binary oxides consisting of $\mathrm{CuO}$ and $\mathrm{CuCr}_{2} \mathrm{O}_{4}$ gave high response speed and high selectivity against $\mathrm{NO}_{2}$. In the $\mathrm{NO}_{2}$ concentration range from 10 to $500 \mathrm{ppm}$, the $90 \%$ response and recovery times were approximately $10 \mathrm{~s}$ at $659{ }^{\circ} \mathrm{C}$ [140]. Diao et al. reported that the addition of $\mathrm{Cr}_{2} \mathrm{O}_{3}$ to $\mathrm{WO}_{3}$ was effective for enhancement in $\mathrm{NO}_{2}$ sensitivity as well as response speed. In this case, as shown in Fig. 17, the maximum improvement in $\mathrm{NO}_{2}$ sensitivity was obtained when the molar ratio of $\mathrm{Cr}$ and $\mathrm{W}$ was $3: 2$ [148]. Besides, the addition of noble metals to SE improved the $\mathrm{NO}_{x}$ sensing characteristics as well. Careful selection of precious metal additives to the NiO-SE revealed that the addition of $3 \mathrm{wt} \% \mathrm{Rh}$ gave a remarkable improvement in the $\mathrm{NO}_{2}$ sensitivity [150].

In order to eliminate the interferences from both reducing and oxidizing gases, several research groups have proposed the adaptation of catalytic filters. Yang and Dutta reported that $\mathrm{NO}_{x}$ selectivity was significantly increased by the use of a gas filter placed upstream sensor cell [80]. The platinum-loaded zeolite Y (PtY) material having an excellent gas-phase catalytic activity was used as a filter to promote oxidation of interference gases (e.g., $\mathrm{CO}$, propane, and $\mathrm{NH}_{3}$ ), meanwhile $\mathrm{WO}_{3}$ was used as an SE material due to its poor catalytic 
Table 3 Typical examples of the mixed-potential type zirconia-based $\mathrm{NO}_{x}$ sensor

\begin{tabular}{|c|c|c|c|c|c|}
\hline $\begin{array}{l}\text { Sensor structure } \\
\text { SE | YSZ | RE }\end{array}$ & $\begin{array}{l}\text { Sensor } \\
\text { configuration }\end{array}$ & Operating temp. $\left({ }^{\circ} \mathrm{C}\right)$ & $\begin{array}{l}\text { Detection range } \\
(\mathrm{ppm})\end{array}$ & Year & Ref. \\
\hline $\mathrm{CdMn}_{2} \mathrm{O}_{4}|\mathrm{YSZ}| \mathrm{Pt}$ & Tubular & $500-600$ & $5-4,000$ & 1996 & {$[45]$} \\
\hline $\mathrm{CdCr}_{2} \mathrm{O}_{4}|\mathrm{YSZ}| \mathrm{Pt}$ & Tubular & $500-600$ & $20-600$ & 1997 & {$[125]$} \\
\hline $\mathrm{Pt}|\mathrm{YSZ}| \mathrm{Pt}$ & Planar & 800 & $0-2,500$ & 1998 & {$[126]$} \\
\hline $\mathrm{WO}_{3}|\mathrm{YSZ}| \mathrm{Pt}$ & Tubular & $500-700$ & $5-200$ & 2000 & {$[127]$} \\
\hline $\mathrm{NiCr}_{2} \mathrm{O}_{4}|\mathrm{YSZ}| \mathrm{Pt}$ & Tubular & $550-650$ & $25-436$ & 2001 & [128] \\
\hline $\mathrm{ZnCr}_{2} \mathrm{O}_{4}|\mathrm{YSZ}| \mathrm{Pt}$ & Tubular & $600-700$ & $50-436$ & 2002 & [129] \\
\hline $\mathrm{ZnFe}_{2} \mathrm{O}_{4}|\mathrm{YSZ}| \mathrm{Pt}$ & Tubular & $600-700$ & $50-436$ & 2002 & {$[130]$} \\
\hline $\mathrm{WO}_{3} / \mathrm{Pt}($ or $\mathrm{Au})|\mathrm{YSZ}| \mathrm{Pt}$ (or $\left.\mathrm{Au}\right)$ & Planar & $500-700$ & $300-1,000$ & 2003 & [131] \\
\hline $\mathrm{V}_{2} \mathrm{O}_{5}\left(+\mathrm{Al}_{2} \mathrm{O}_{3}\right)|\mathrm{YSZ}| \mathrm{Pt}$ & Tubular & $440-460$ & $0-1,000$ & 2003 & [132] \\
\hline $\mathrm{Cr}_{2} \mathrm{O}_{3}|\mathrm{YSZ}| \mathrm{Pt}$ & Planar & $450-650$ & 500 & 2003 & [133] \\
\hline $\mathrm{Cr}_{2} \mathrm{O}_{3}|\mathrm{YSZ}| \mathrm{Pt}$ & Planar & 600 & $10-200$ & 2003 & [134] \\
\hline $\mathrm{Cr}_{2} \mathrm{O}_{3}|\mathrm{YSZ}| \mathrm{Pt}$ & Tubular & 500 & $200-800$ & 2004 & [52] \\
\hline $\mathrm{La}_{0.8} \mathrm{Sr}_{0.2} \mathrm{FeO}_{3}|\mathrm{YSZ}| \mathrm{Pt}$ & Planar & $450-700$ & $20-1,000$ & 2004 & [135] \\
\hline $\mathrm{ZnO}|\mathrm{YSZ}| \mathrm{Pt}$ & Tubular & $600-700$ & $40-450$ & 2004 & [136] \\
\hline $\mathrm{LaFeO}_{3}|\mathrm{YSZ}| \mathrm{Pt}$ & Planar & $450-700$ & $20-1,000$ & 2004 & {$[137,138]$} \\
\hline $\mathrm{NiO}|\mathrm{YSZ}| \mathrm{Pt}$ & Planar & $700-900$ & $10-400$ & 2005 & {$[76,139]$} \\
\hline $\mathrm{La}_{0.8} \mathrm{Sr}_{0.2} \mathrm{CrO}_{3}|\mathrm{YSZ}| \mathrm{Pt}$ & Planar & $450-650$ & $0-500$ & 2006 & [54] \\
\hline $\mathrm{CuO}-\mathrm{CuCr}_{2} \mathrm{O}_{4}|\mathrm{ScSZ}| \mathrm{Pt}$ & Planar & $518-659$ & $10-500$ & 2006 & {$[140]$} \\
\hline $\mathrm{NiO}(+\mathrm{Au})|\mathrm{YSZ}| \mathrm{Pt}$ & Planar & $600-800$ & $50-400$ & 2008 & [141] \\
\hline $\mathrm{Au}|\mathrm{YSZ}| \mathrm{Pt}$ & Planar & 600 & $50-400$ & 2008 & [142] \\
\hline $\mathrm{La}_{0.6} \mathrm{Ca}_{0.4} \mathrm{Mn}_{1-x} \mathrm{Me}_{x} \mathrm{O}_{3}|\mathrm{YSZ}| \mathrm{Pt}$ & Planar & 550 & $50-800$ & 2008 & [143] \\
\hline $\mathrm{NiO}(+\mathrm{YSZ})|\mathrm{YSZ}| \mathrm{Pt}$ & Planar & 700 & $100-500$ & 2009 & [16] \\
\hline $\mathrm{NiO}(+\mathrm{Cr})|\mathrm{YSZ}| \mathrm{Pt}$ & Planar & $800-900$ & $50-400$ & 2009 & [144] \\
\hline $\mathrm{Ni}_{1-x} \mathrm{Co}_{x} \mathrm{O}|\mathrm{YSZ}| \mathrm{Pt}$ & Planar & 800 & $10-400$ & 2009 & [145] \\
\hline $\mathrm{La}_{2} \mathrm{CuO}_{4}|\mathrm{YSZ}| \mathrm{Pt}$ & Planar & $400-600$ & $50-400$ & 2011 & [59] \\
\hline $\mathrm{CuO}|\mathrm{YSZ}| \mathrm{Pt}$ & Planar & 550 & $10-100$ & 2012 & {$[146]$} \\
\hline $\mathrm{SmFeO}_{3}|\mathrm{YSZ}| \mathrm{Pt}$ & Planar & $300-500$ & $30-90$ & 2013 & [99] \\
\hline $\mathrm{MnCr}_{2} \mathrm{O}_{4}|\mathrm{YSZ}| \mathrm{Pt}$ & Planar & 650 & $5-600$ & 2013 & [147] \\
\hline $\mathrm{WO}_{3}-\mathrm{Cr}_{2} \mathrm{O}_{3}|\mathrm{YSZ}| \mathrm{Pt}$ & Planar & 800 & $20-300$ & 2013 & [148] \\
\hline
\end{tabular}

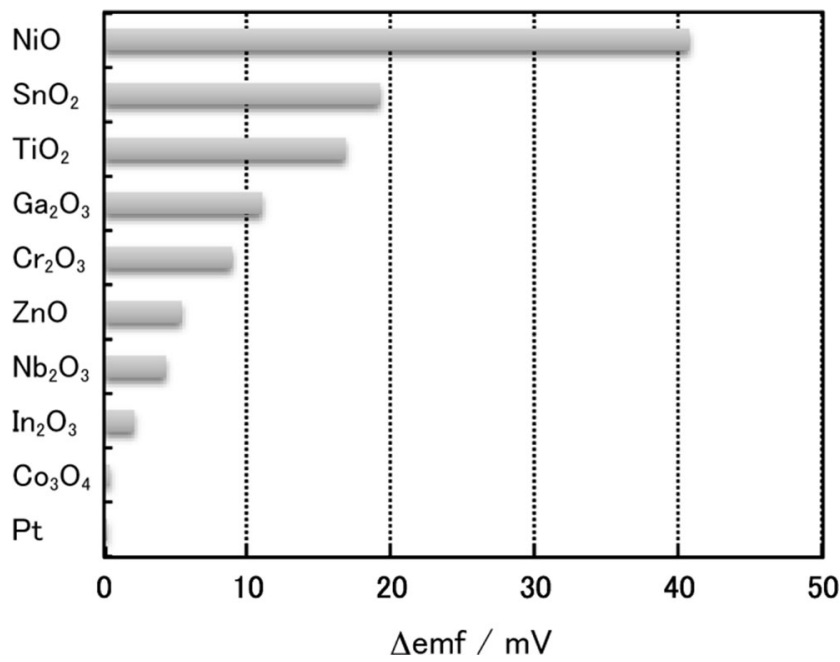

Fig. 15 Comparison of $\Delta \mathrm{emf}$ to $400 \mathrm{ppm} \mathrm{NO} \mathrm{N}_{2}$ at $850{ }^{\circ} \mathrm{C}$ in dry air with $21 \mathrm{vol} \%$ of $\mathrm{O}_{2}$ for the sensors using each of various single metal oxide SEs. [Reproduced from [149], Copyright 2006, with permission from Elsevier] activity against the gas-phase reactions involving $\mathrm{NO}_{x}$. When the gases were passing through the PtY filter, their responses were effectively minimized. As shown in Fig. 18, the interference of propane could almost be eliminated when the temperature of the PtY filter was maintained at $400{ }^{\circ} \mathrm{C}$.

Sekhar et al. examined the influence of the porosity of YSZ on the sensitivity and the response speed for the $\mathrm{NO}_{x}$ sensor attached with $\mathrm{La}_{0.8} \mathrm{Sr}_{0.2} \mathrm{CrO}_{3}$-SE [16]. In this sensor, the response speed was enhanced with increasing YSZ porosity. Such an improvement in sensing performances seemed to be due to the increase in diffusibility of target gas through the porous YSZ sintered at lower temperature. Park et al. also reported that the addition of YSZ powder into NiO-SE enhanced the response speed and gas sensitivity [15]. When $15 \mathrm{~mol} \%$ YSZ was added to NiO-SE, the obtained sensor showed the maximum sensing performance because of the attainment of appropriate condition of reaction sites at the YSZ/NiO-SE interface. 
Fig. 16 (Left) SEM images of NiO-SE after sintered at each temperature. (Right) Cross sensitivities to various gases (400 ppm each) at $800{ }^{\circ} \mathrm{C}$ under the wet condition of $5 \mathrm{vol} \%$ water vapor. Sintering temperature of $\mathrm{NiO}$ are $\mathbf{a} 800{ }^{\circ} \mathrm{C} ; \mathbf{b} 1,100{ }^{\circ} \mathrm{C}$; c $1,400{ }^{\circ} \mathrm{C}$, for $2 \mathrm{~h}$ in air.

[Reproduced from [153],

Copyright 2010, with permission from Elsevier]

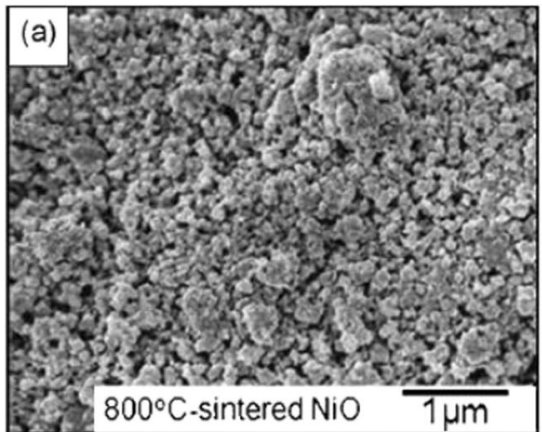

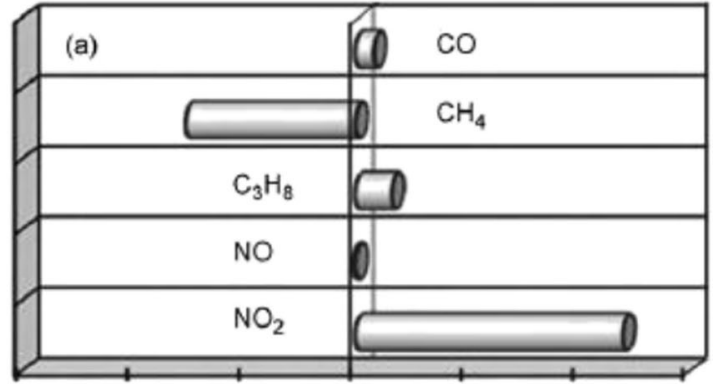
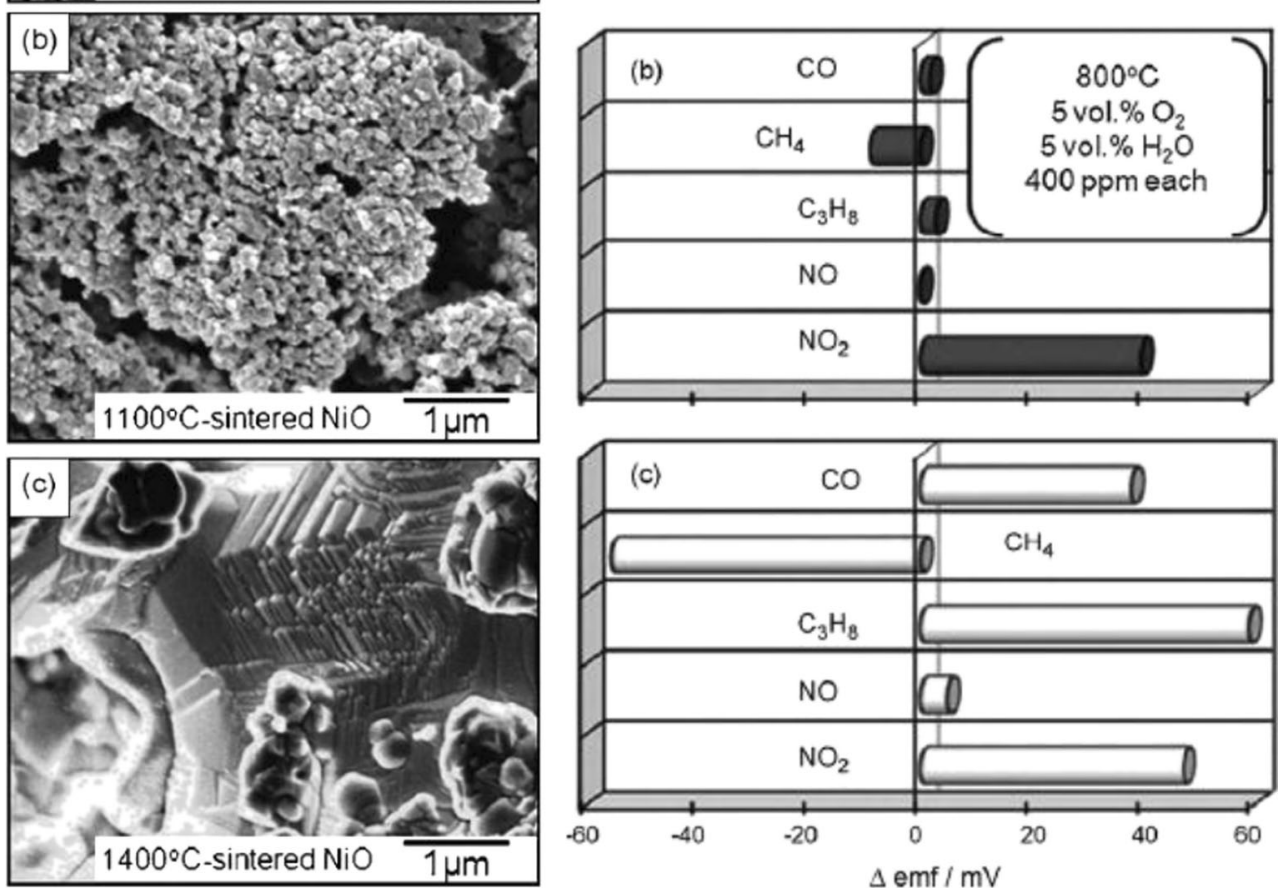

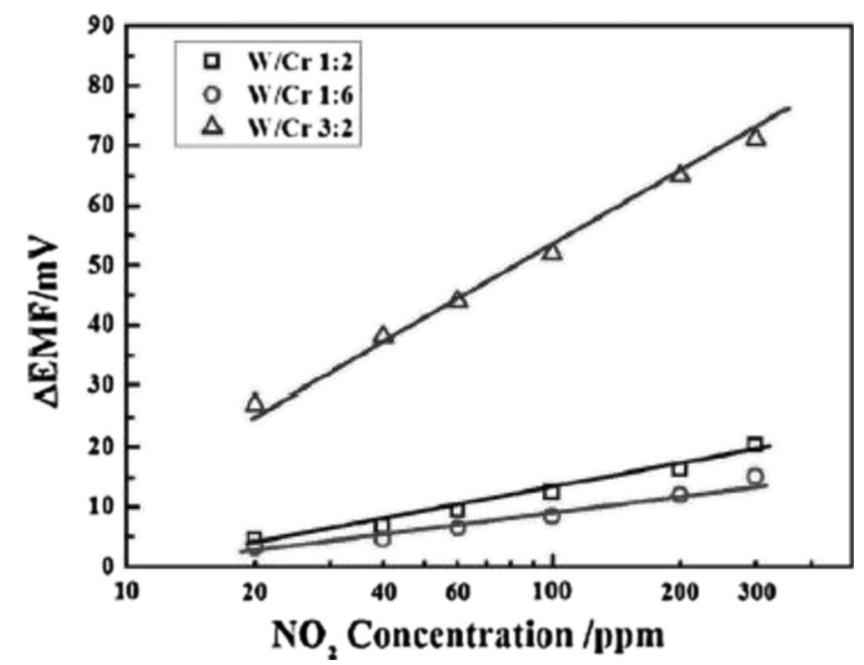

Fig. 17 Dependence of $\Delta \mathrm{emf}$ on $\mathrm{NO}_{2}$ concentration at $800{ }^{\circ} \mathrm{C}$ for the sensors attached with $\mathrm{Cr}_{2} \mathrm{O}_{3}-\mathrm{WO}_{3}$ nanocomposite SEs sintered at $1,000{ }^{\circ} \mathrm{C}$. [Reprinted from [148], Copyright 2013, with permission from Elsevier]

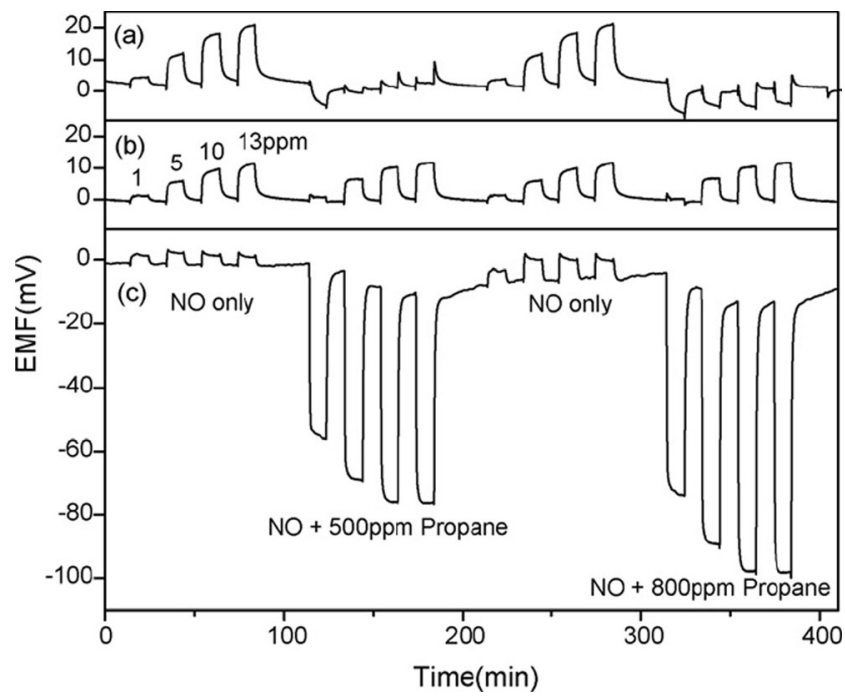

Fig. 18 Response transients to $1-13 \mathrm{ppm} \mathrm{NO}$ in the presence of $3 \mathrm{vol} \%$ $\mathrm{O}_{2}$ and propane. a 500 and $800 \mathrm{ppm}$ propane with the $\mathrm{PtY}$ filter at $300^{\circ} \mathrm{C}$; b 500 and $800 \mathrm{ppm}$ propane with the PtY filter at $400{ }^{\circ} \mathrm{C}$; c 500 and $800 \mathrm{ppm}$ propane without the filter. [Reprinted from [80], Copyright 2007, with permission from Elsevier] 
Considering all current findings by various international research groups, it has been concluded that both of the chemical composition and the structural morphology of the SE material are crucial factors for further improvement in the sensing characteristics of the mixed-potential type YSZbased $\mathrm{NO}_{x}$ sensors. In addition, it was found that the sensing characteristics of nano-structured SE materials were quite different from their bulk samples [121, 141]. For instance, the nano-structured Au-SE fabricated by a radiofrequency sputtering technique exhibited remarkable sensitivity and selectivity toward $\mathrm{NO}_{2}$, while the bulk sample had no gas selectivity [142]. Thus, it still remains for a future work to reveal the sensing characteristics of nano-structured SE materials which are capable of providing further enhancement in the sensor characteristics.

\section{$\mathrm{H}_{2}$ sensor}

Similar to the other mixed-potential type sensors, early development of the YSZ-based $\mathrm{H}_{2}$ sensor was evolved around the utilization of noble metal such as Pt for SE of the sensor, as reported by Vogel et al. [36]. Recently, investigation on the performance of micro-structured Au mesh as an SE component for the planar configuration of mixed-potential type YSZbased sensor has been reported by Breedon and Miura; the developed sensor generated sensitive and selective response to $\mathrm{H}_{2}$ [154]. Inspired by the sensor construction developed by Okamoto et al. [33], Tan and Tan have fabricated and studied the YSZ-based sensor using Pt-SE covered with an oxidebased $\left(\mathrm{ZnO}-\mathrm{CuO}-\mathrm{Al}_{2} \mathrm{O}_{3}\right)$ catalyst layer [38]. This sensor confirmed to be capable of providing $\mathrm{H}_{2}$ response at parts per million level. Using a different SE configuration, $\mathrm{Lu}$ et al. reported that the YSZ-based sensors attached with metal oxides (such as $\mathrm{ZnO}$ ) covered with noble metal mesh $(\mathrm{Pt})$ also exhibited sensitive response toward $\mathrm{H}_{2}$ [83].

The expensive material cost for the sensor using noble metal SE (including catalyst and current collector) has become one of the motivation for utilization of inexpensive metal oxides as the SE materials [83, 155-157]. Recent similar finding regarding the utilization of oxide-SEs was also reported by Fadeyev et al.; the sensors using single-oxide SEs such as $\mathrm{ZnO}$ and $\mathrm{SnO}_{2}$ generated higher $\mathrm{H}_{2}$ responses, compared with other examined single oxides [155]. The development of YSZ-based sensors aiming at $\mathrm{H}_{2}$ detection is summarized in Table 4.

Apart from the employment of oxides as a single-phase SE, they can also be combined with metal as a composite SE. For example, Zosel et al. reported the utilization of the composite $\mathrm{SE}$ comprising Au and metal oxide in a planar sensor configuration [158]. As shown in Fig. 19, the composite SEs using $\mathrm{Au}$ and some oxides (such as $\mathrm{Nb}_{2} \mathrm{O}_{5}$ and $\mathrm{Ta}_{2} \mathrm{O}_{5}$ ) were reported to yield higher $\mathrm{H}_{2}$ sensitivity, compared with the other oxides examined [158].

Further exploration on $\mathrm{H}_{2}$ sensing materials has made by Sorita and Kawano who successfully utilized perovskite and spinel oxides as SE materials for the YSZ-based $\mathrm{H}_{2}$ sensor $[49,50]$. Among investigated oxides, only $\mathrm{ZnFe}_{2} \mathrm{O}_{4}$ has showed slightly higher sensitivity toward $\mathrm{H}_{2}$ than to $\mathrm{CO}$ at $500{ }^{\circ} \mathrm{C}$. Interestingly, $\mathrm{ZnFe}_{2} \mathrm{O}_{4}$ was confirmed to have a greater catalytic activity toward $\mathrm{H}_{2}$ oxidation than to $\mathrm{CO}$ oxidation. This fact suggests that the higher response to $\mathrm{H}_{2}$ than to $\mathrm{CO}$ may be due to the greater number of preferential site particularly facilitating the electrochemical reaction of $\mathrm{H}_{2}$ than that of $\mathrm{CO}$ at the $\mathrm{ZnFe}_{2} \mathrm{O}_{4} / \mathrm{YSZ}$ interface. The detailed investigation confirming the underlying mechanism of these interesting phenomena has yet to be reported.

Additionally, solid solution such as indium tin oxide (ITO) has also been proposed as an alternative prospective $\mathrm{H}_{2}$ -

Table 4 Comparison of mixed-potential type YSZ-based sensors using various SE materials for $\mathrm{H}_{2}$ detection using different configurations

\begin{tabular}{|c|c|c|c|c|c|}
\hline $\begin{array}{l}\text { Sensor structure } \\
\text { SE | YSZ | RE }\end{array}$ & $\begin{array}{l}\text { Sensor } \\
\text { configuration }\end{array}$ & Operating temp. $\left({ }^{\circ} \mathrm{C}\right)$ & $\begin{array}{l}\text { Detection range } \\
(\mathrm{ppm})\end{array}$ & Year & Ref. \\
\hline $\mathrm{Pt}-\mathrm{Au}|\mathrm{YSZ}| \mathrm{Pt}$ & Tubular & 550 & $0-1,000$ & 1993 & {$[36]$} \\
\hline $\mathrm{CuO}-\mathrm{ZnO}-\mathrm{Al}_{2} \mathrm{O}_{3} / \mathrm{Pt}|\mathrm{YSZ}| \mathrm{Pt}$ & Planar & $415-500$ & $0-150$ & 1994 & {$[38]$} \\
\hline $\mathrm{ZnO}|\mathrm{YSZ}| \mathrm{Pt}$ & Tubular & $400-600$ & $50-500$ & 1996 & [83] \\
\hline ITO $\mid$ YSZ | Ag & Planar & 500 & $200-2,000$ & 2004 & {$[157]$} \\
\hline ITO $\mid$ YSZ $\mid \mathrm{Pt}$ & Planar & $450-550$ & $200-27,000$ & 2005 & {$[156]$} \\
\hline ITO $\mid$ YSZ $\mid \mathrm{Pt}$ & Planar & 535 & $1,000-20,000$ & 2010 & {$[159]$} \\
\hline $\mathrm{SnO}_{2}(+\mathrm{YSZ})|\mathrm{YSZ}| \mathrm{NiO}-\mathrm{TiO}_{2}$ & Combined & 600 & $20-800$ & 2012 & {$[161]$} \\
\hline Au-mesh | YSZ | Pt & Planar & 550 & $10-400$ & 2013 & {$[154]$} \\
\hline $\mathrm{Cr}_{2} \mathrm{O}_{3} / \mathrm{Al}_{2} \mathrm{O}_{3} / \mathrm{SnO}_{2}(+\mathrm{YSZ})|\mathrm{YSZ}| \mathrm{Pt}$ & Tubular & 550 & $20-800$ & 2013 & {$[162]$} \\
\hline $\mathrm{ZnO}-\mathrm{Zn}_{3} \mathrm{Ta}_{2} \mathrm{O}_{8}|\mathrm{YSZ}| \mathrm{Pt}$ & Tubular & 600 & $20-100$ & 2013 & {$[180]$} \\
\hline $\mathrm{ZnO}+\left(+\mathrm{Ta}_{2} \mathrm{O}_{5}\right)|\mathrm{YSZ}| \mathrm{Pt}$ & Tubular & 500 & $10-400$ & 2013 & {$[163]$} \\
\hline
\end{tabular}

ITO indium tin oxide or tin-doped indium oxide 
$\mathrm{MeO}$ for $\mathrm{Au}-\mathrm{MeO}$ composite

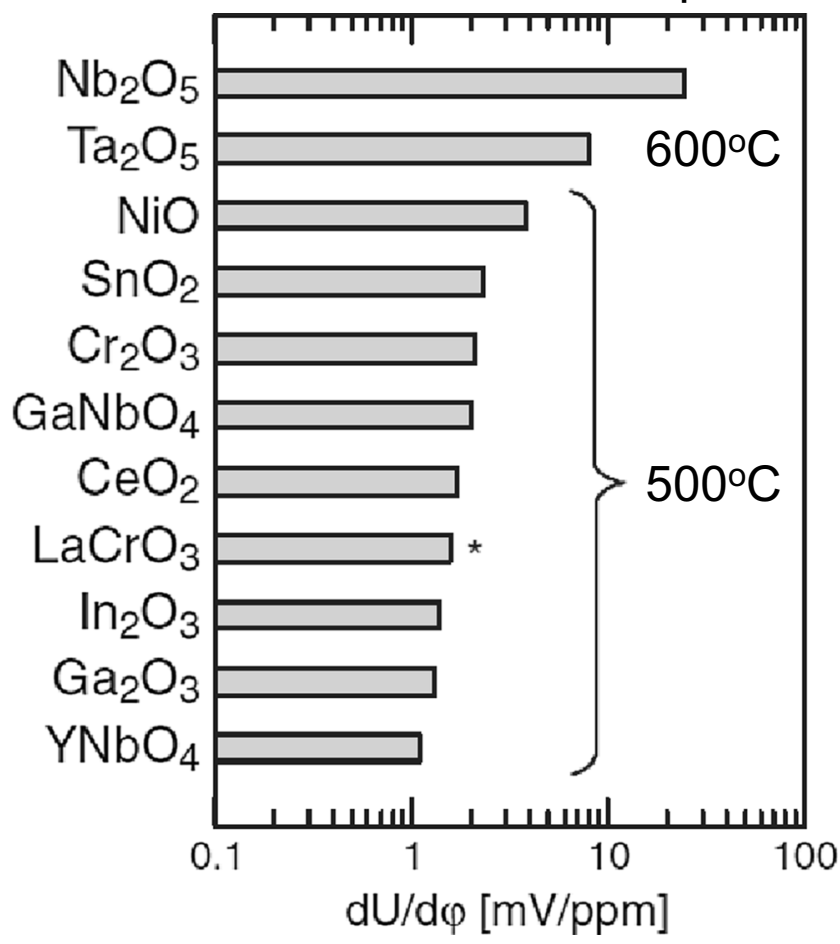

Fig. 19 Comparison of $\mathrm{H}_{2}$ sensitivity of the YSZ-based sensors using each of composites of Au-oxide as SE. [Reproduced from [158], Copyright 2006, with permission from Elsevier]

sensitive SE material [156, 157, 159, 160]. Martin et al. reported that the utilization of ITO as SE and Ag as RE in a planar sensor configuration can detect $\mathrm{H}_{2}$ in the range of 2002,000 ppm at $460{ }^{\circ} \mathrm{C}$ [157]. The $\mathrm{H}_{2}$ sensitivity of the present

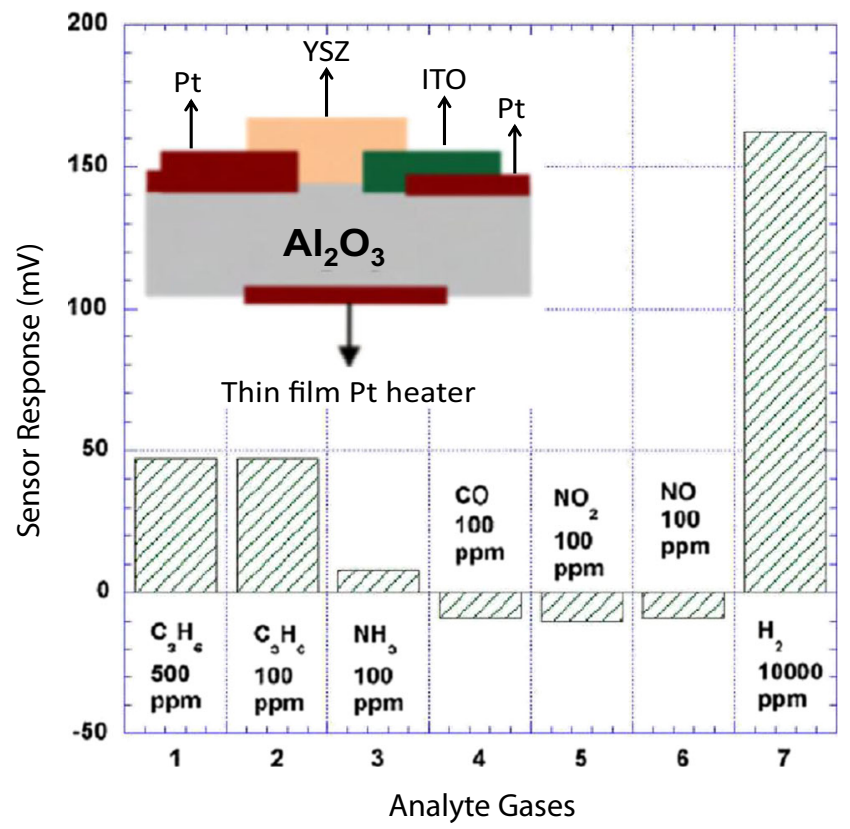

Fig. 20 Cross sensitivity of ITO|YSZ|Pt sensor toward different examined gases. (Inset is a schematic setup of the developed sensor). [Reproduced from [159], Copyright 2010, with permission from Elsevier] sensor was found to be unaffected by the presence of humidity. Furthermore, when Pt was used as the RE material for the sensor attached with thin ITO-SE ( $2 \mu \mathrm{m}$ thickness $)$, the sensor exhibited higher response to $\mathrm{H}_{2}$, compared with that using Ag$\mathrm{RE}$ [156]. This sensor could detect $\mathrm{H}_{2}$ in the wide concentration range from $300 \mathrm{ppm}$ to $5.5 \mathrm{vol} \% \mathrm{H}_{2}$ in air at $600{ }^{\circ} \mathrm{C}$.

Alternative strategy in obtaining high-performance $\mathrm{H}_{2}$ sensor was proposed by Sekhar et al., by using a novel sensor configuration comprising ITO-SE and Pt-RE combined with an integrated Pt heater, as shown in Fig. 20 [159, 160]. This uniquely designed sensor employs dense SE together with the porous YSZ layer (an inset of Fig. 20) [159]. This particular design is expected to reduce the counter-productive effect of heterogeneous catalysis that generally occurs within the porous oxide-SE. This sensor could detect $\mathrm{H}_{2}$ sensitively with small or negligible responses toward the other gases examined. The reported sensor was capable of detecting $\mathrm{H}_{2}$ in the concentration range of $0.15-2 \mathrm{vol}^{\circ} \mathrm{H}_{2}$ with the response time as fast as 3-7 s. The effect of the sensor packaging on the sensing performance of the ITO|YSZ|Pt sensor has also been tested and compared with the commercial $\mathrm{H}_{2}$ sensor.

Despite of the progresses made in the development of a highly sensitive $\mathrm{H}_{2}$ sensor based on YSZ, providing a selective signal is another challenge. Methods that have recently been reported are proven to be effective in diminishing the unwanted responses from the interfering gases. Inspired by the previous success of the combined electrode configuration in attaining selective CO response [84, 101], similar configuration was then reported by Yamaguchi et al. [161]. The sensor using $\mathrm{SnO}_{2}$ (+YSZ)-SE sensitive to $\mathrm{H}_{2}$ and $\mathrm{C}_{3} \mathrm{H}_{8}$ was paired with $\mathrm{NiO}\left(+\mathrm{TiO}_{2}\right)-\mathrm{SE}$ that was confirmed to be sensitive and selective toward $\mathrm{C}_{3} \mathrm{H}_{8}$. The resulting combined-type YSZbased sensor has been successful in generating the selective response to $\mathrm{H}_{2}$.

Another effective strategy in enhancing the selectivity was attempted by the use of a catalyst layer coated on the SE layer

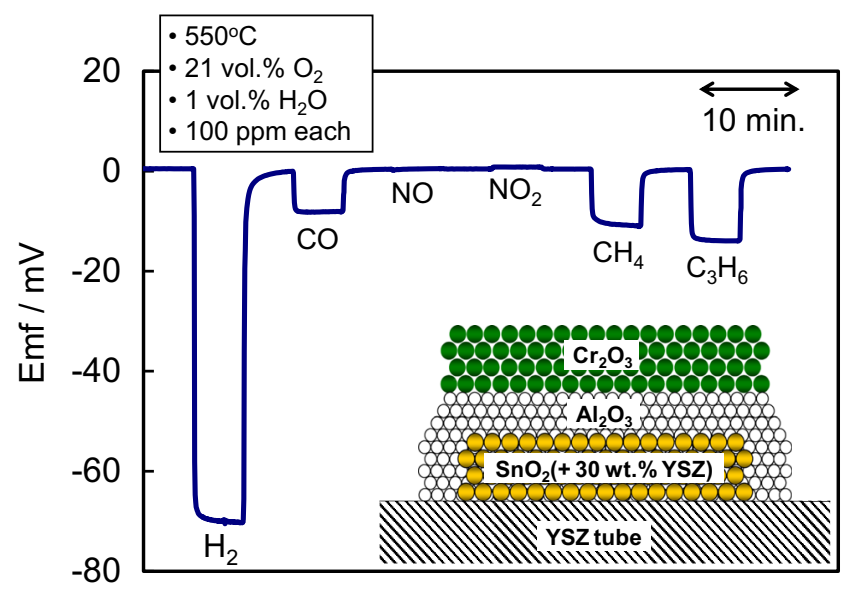

Fig. 21 Cross sensitivity of the sensor using $\mathrm{Cr}_{2} \mathrm{O}_{3} / \mathrm{Al}_{2} \mathrm{O}_{3} / \mathrm{SnO}_{2}(+\mathrm{YSZ})-$ $\mathrm{SE}$. (inset is the construction of the sensor). [Reproduced from [162], Copyright 2013, with permission from Elsevier] 
Fig. 22 a Change of emf with aging time and $\mathbf{b}$ comparison of cross sensitivity for the sensor using $\mathrm{ZnTa}_{2} \mathrm{O}_{6}$-based-SE before and after the aging. [Reproduced from [163] and [86], Copyright 2013, with permission from Elsevier and The American Chemical Society]
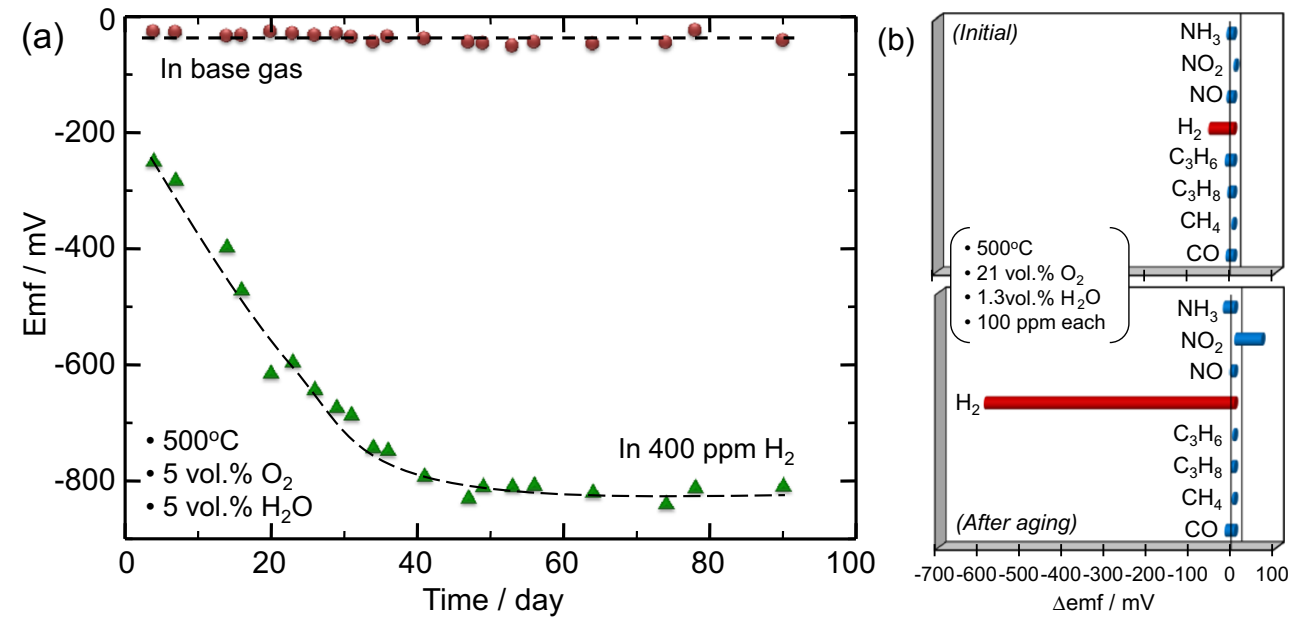

$[33,38,49]$. Yamaguchi et al. also reported that the direct deposition of $\mathrm{Cr}_{2} \mathrm{O}_{3}$ catalyst layer on the top of $\mathrm{SnO}_{2}$-SE was found to provide an adverse effect on the $\mathrm{H}_{2}$ sensing characteristics; this sensor suffered from the deteriorated sensing performances possibly owing to the penetration of $\mathrm{Cr}_{2} \mathrm{O}_{3}$ into the SE layer and reaching the $\mathrm{SnO}_{2} / \mathrm{YSZ}$ interface [162]. The proposed preventative method was the use of an additional $\mathrm{Al}_{2} \mathrm{O}_{3}$ layer that enveloped the sensing layer $\left(\mathrm{SnO}_{2}\right)$ to prevent from intrusion of $\mathrm{Cr}_{2} \mathrm{O}_{3}$ (an inset of Fig. 21). As a result, the sensor using $\mathrm{Cr}_{2} \mathrm{O}_{3} / \mathrm{Al}_{2} \mathrm{O}_{3} / \mathrm{SnO}_{2}(+\mathrm{YSZ})$-SE exhibited an improved selective response toward $\mathrm{H}_{2}$, as given in Fig. 21 [162].

Quite recently, Anggraini et al. have reported that a highly selective $\mathrm{H}_{2}$ response can be achieved after a long-term aging of the sensor. As shown in Fig. 22, the long-term aging (more than about 40 days at $500{ }^{\circ} \mathrm{C}$ ) of the sensor using $\mathrm{ZnO}(+$ $84 \mathrm{wt} \% \mathrm{Ta}_{2} \mathrm{O}_{5}$ )-SE was found to increase significantly both of sensitivity and selectivity toward $\mathrm{H}_{2}[86,163]$. The change of the chemical surface state of the $\mathrm{Zn}$-Ta-O-based-SE suggested the transformation of a non-equilibrated $\mathrm{Zn}-\mathrm{Ta}-\mathrm{O}$ compound at the initial state into a fully equilibrated stable one after the long-term aging. Since the catalytic activity toward electrochemical reaction of $\mathrm{H}_{2}$ (or $\mathrm{O}_{2}$ ) was barely affected by the aging, the change in the chemical surface state of the SE was believed to strongly correspond with the decrease in the catalytic activity to the gas-phase oxidation of $\mathrm{H}_{2}$. Such a lower heterogeneous catalytic activity leads to higher fraction of $\mathrm{H}_{2}$ which can reach and react at the SE/YSZ interface, resulting in extremely high $\mathrm{H}_{2}$ sensitivity [86].

Another alternative method to minimize the cross selectivity to other gases is proposed by Fischer et al. by means of a pulse-discharged technique [164]. In this approach, a positive DC voltage was applied between two electrodes for a certain period of time and then disconnected. The self-discharge process will occur afterward and the sensitivity to each gas can be measured during this period. The same procedure was repeated when a negative voltage was applied. The sensing characteristics of such a sensor to one gas during this discharge period can be quite different from those to another gas. This makes a particular target gas distinguishable from coexisting other gases in a gas mixture.

Apart from being able to detect $\mathrm{H}_{2}$ sensitively and selectively, a high-performance YSZ-based $\mathrm{H}_{2}$ sensor is also defined by its ability to provide a rapid sensing signal. One example of an excellent result pertaining this aspect is reported by Martin and Glass; the developed sensor using ITO-SE could detect $1 \mathrm{vol} \% \mathrm{H}_{2}$ at $500{ }^{\circ} \mathrm{C}$ in less than $1 \mathrm{~s}$ [156].
Fig. 23 Schematic view of a total system for removal and monitoring of exhaust gases

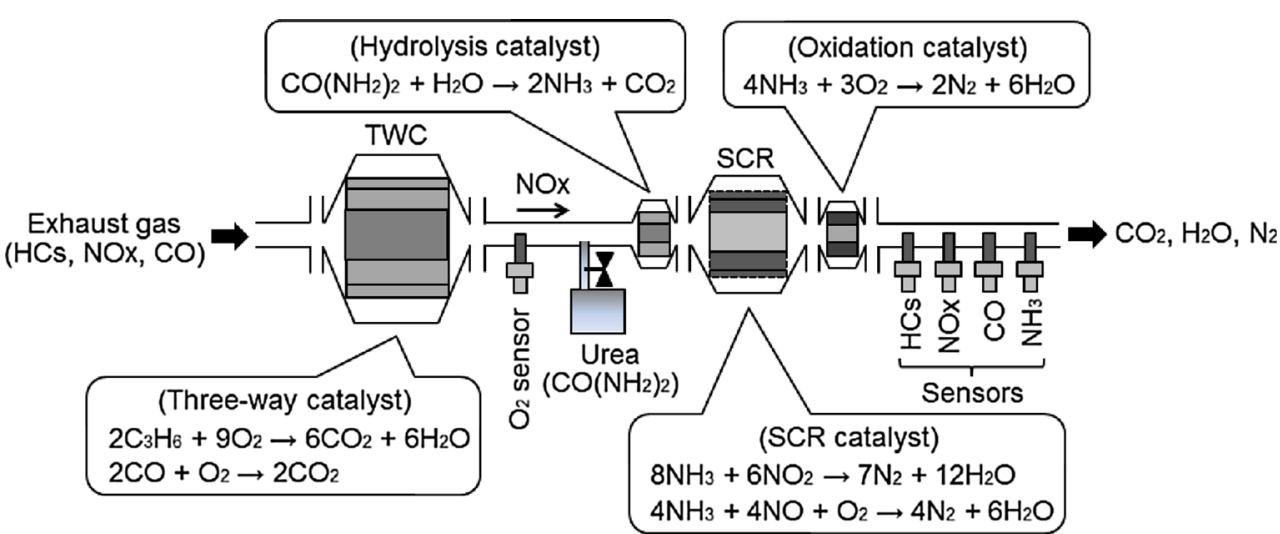


Table 5 Typical examples of the mixed-potential type YSZ-based $\mathrm{NH}_{3}$ sensors

\begin{tabular}{|c|c|c|c|c|c|}
\hline $\begin{array}{l}\text { Sensor structure } \\
\text { SE | YSZ | RE }\end{array}$ & $\begin{array}{l}\text { Sensor } \\
\text { configuration }\end{array}$ & $\begin{array}{l}\text { Operating } \\
\text { temp. }\left({ }^{\circ} \mathrm{C}\right)\end{array}$ & $\begin{array}{l}\text { Detection range } \\
(\mathrm{ppm})\end{array}$ & Year & Ref. \\
\hline $\mathrm{MoO}_{3}|\mathrm{YSZ}| \mathrm{Pt}$ & Tubular & 500 & $10-100$ & 2006 & {$[167]$} \\
\hline $\mathrm{NiO} / \mathrm{Au}|\mathrm{YSZ}| \mathrm{Pt}$ & Planar & 800 & $20-100$ & 2008 & [168] \\
\hline $\mathrm{VWT} / \mathrm{Au}|\mathrm{YSZ}| \mathrm{Au}$ & Planar & 550 & $20-300$ & 2009,2013 & {$[57,166]$} \\
\hline Nano-Au | YSZ(111) | Pt & Planar & 700 & 400 & 2009 & [121] \\
\hline $\mathrm{Pt} \mid \mathrm{H}_{3} \mathrm{PO}_{4}$ treated-YSZ $\mid \mathrm{Pt}$ & Tubular & 600 & $10-200$ & 2009 & [169] \\
\hline $\mathrm{Au}|\mathrm{YSZ}| \mathrm{Pt}$ & Planar & 600 & $25-100$ & 2010 & {$[170]$} \\
\hline $\mathrm{Au}\left(+\mathrm{Bi}_{2} \mathrm{O}_{3}\right)|\mathrm{YSZ}| \mathrm{Pt}$ & Tubular & 600 & $250-1,000$ & 2011 & {$[171]$} \\
\hline Nano-Au(+nano- $\left.\mathrm{SiO}_{2}\right)|\mathrm{YSZ}| \mathrm{Pt}$ & Planar & 675 & $20-200$ & 2011 & {$[172]$} \\
\hline $\mathrm{CoWO}_{4}|\mathrm{YSZ}| \mathrm{Pt}$ & Planar & 700 & $100-1,000$ & 2012 & [173] \\
\hline $\mathrm{In}_{2} \mathrm{O}_{3}|\mathrm{YSZ}| \mathrm{LaCoO}_{3}$ & Combined & 700 & $100-300$ & 2013 & [62] \\
\hline
\end{tabular}

$V W T \mathrm{~V}_{2} \mathrm{O}_{5}-\mathrm{WO}_{3}-\mathrm{TiO}_{2}$

In summary, obtaining excellent features in terms of sensitivity, selectivity, quick response/recovery time, and long-term stability will always be the challenges in the development of high-performance YSZ-based $\mathrm{H}_{2}$ sensors. However, the ongoing researches regarding SE materials, sensor's designs and fabricating technologies can ensure to overcome those challenges.

\section{$\mathrm{NH}_{3}$ sensor}

In order to decompose various hazardous gases (such as $\mathrm{HCs}$, $\mathrm{NO}_{x}$, and $\mathrm{CO}$ ) exhausted from automobiles, a three-way catalyst (TWC) utilizing $\mathrm{Pt}, \mathrm{Pd}$, and $\mathrm{Rh}$ is installed midstream of an exhaust pipe (Fig. 23). However, TWC cannot remove $\mathrm{NO}_{x}$ effectively from diesel-engine or gasoline-engine exhausts under lean-burn (air-rich) conditions. Recently, a unique $\mathrm{DeNO}_{x}$ system which can operate effectively even under such

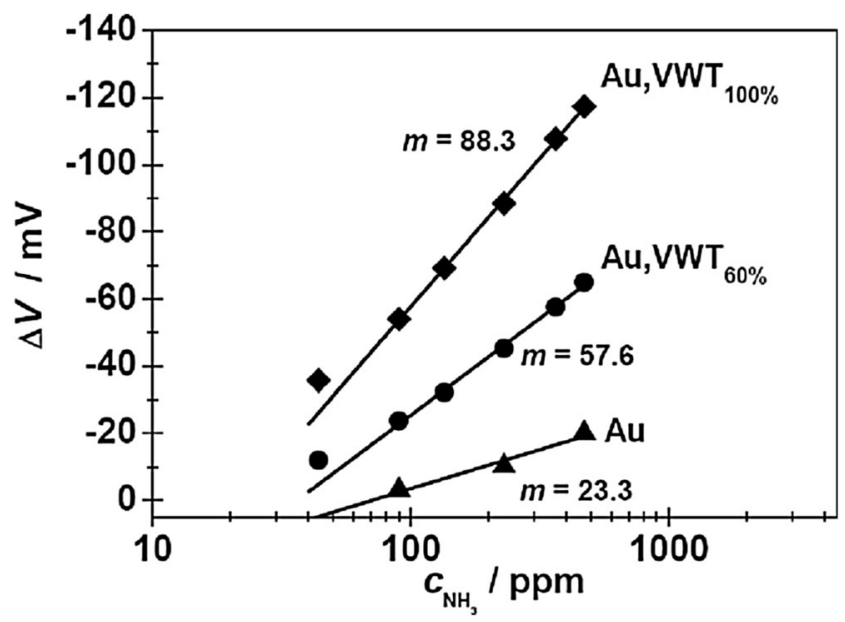

Fig. 24 Dependence of sensitivity on $\mathrm{NH}_{3}$ concentration for the YSZbased sensors using each of Au-SE and VWT/Au-SE, operated at $550{ }^{\circ} \mathrm{C}$. [Reproduced from [166], Copyright 2013] a lean-burn condition has been developed and installed into vehicles, referred as a selective catalytic reduction (SCR) system [165]. In this system, the thermal hydrolization of an aqueous urea solution generates $\mathrm{NH}_{3}$ and the produced $\mathrm{NH}_{3}$ gas reacts with $\mathrm{NO}_{x}$, converting to the environmentally safe $\mathrm{N}_{2}$ and $\mathrm{H}_{2} \mathrm{O}$, as schematically presented in Fig. 23. However, the excessive injection of urea will cause the emission of unreacted (slip) $\mathrm{NH}_{3}$ to atmospheric environments, if the $\mathrm{NH}_{3}$ oxidation catalyst located downstream of the SCR catalyst does not work properly. In order to monitor the concentration of harmful slip $\mathrm{NH}_{3}$, the development of a highly sensitive, selective, and stable $\mathrm{NH}_{3}$ sensor is in a strong demand in recent years. Table 5 summarizes the typical examples of mixed-potential type YSZ-based $\mathrm{NH}_{3}$ sensors which have been developed recently in order to satisfy these requirements and needs [57, 62, 121, 166-173].

So far, several methodologies were applied to obtain high $\mathrm{NH}_{3}$ sensitivity. Kida et al. and Diao et al. have reported that thin $\mathrm{MoO}_{3}$-SE layer $(200 \mathrm{~nm})$ [167] and $\mathrm{CoWO}_{4}$-SE

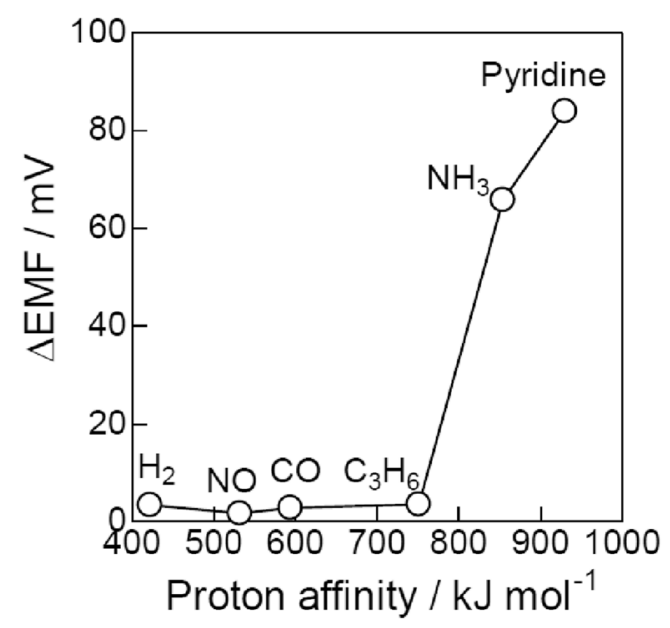

Fig. 25 Relationship between sensitivity and proton affinity to different gases. [Reproduced from [171], Copyright 2011] 
Fig. 26 a Cross sensitivities to various gases at $675^{\circ} \mathrm{C}$ in the presence of $5 \mathrm{vol} \%$ water vapor, for the polished-polycrystalline (pp)-YSZ based sensor treated with $5 \mathrm{~nm}$ Au colloids after 75 days of operation. $\mathbf{b}$ Representative SEM and BSSEM images of an in situ nanocomposite $\left(\mathrm{Au}+\mathrm{SiO}_{2}\right)$ particle formed spontaneously on the surface of pp-YSZ after 75 days of operation of the sensor at $700{ }^{\circ} \mathrm{C}$. [Reproduced from [172], Copyright 2011, with permission from The Royal Society of Chemistry 2011] (b)

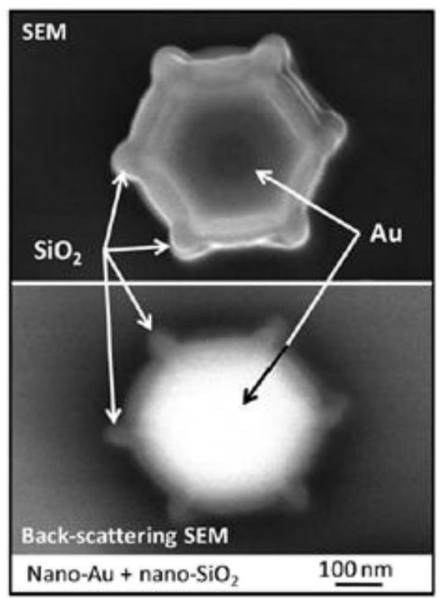

comprised of the large particles $(2-10 \mu \mathrm{m})$ [173], respectively, can facilitate an increase in the $\mathrm{NH}_{3}$ sensitivity of the YSZbased sensors. If $\mathrm{SE}$ is a thin layer and/or has a low surface area, a gas-phase catalytic reaction through the SE layer will be suppressed, resulting in an increase of $\mathrm{NH}_{3}$ sensitivity. Different methodology to enhance $\mathrm{NH}_{3}$ sensitivity is to fabricate unique sensor geometry; a combination of a dense SE with a porous YSZ, reported by Garzon et al. [170]. This particular sensor structure largely contributed to obtain high $\mathrm{NH}_{3}$ sensitivity. In another approach, Schönauer et al. reported that the $\mathrm{NH}_{3}$ sensitivity increased from -20 to $-120 \mathrm{mV}$ toward $470 \mathrm{ppm} \mathrm{NH}_{3}$ by the lamination of a catalyst layer composed of $\mathrm{V}_{2} \mathrm{O}_{5}-\mathrm{WO}_{3}-\mathrm{TiO}_{2}$ (VWT) onto Au-SE, as clearly shown in Fig. 24 [57, 166]. VWT is well-known as an effective SCR catalyst [174] and it is believed to produce activated $\mathrm{NH}_{3}$ species, resulting in an increase in electrochemical activity of $\mathrm{SE}$ against $\mathrm{NH}_{3}$.

Since an automobile exhaust gas is consisting of various gaseous components, the practical efficient $\mathrm{NH}_{3}$ sensor is

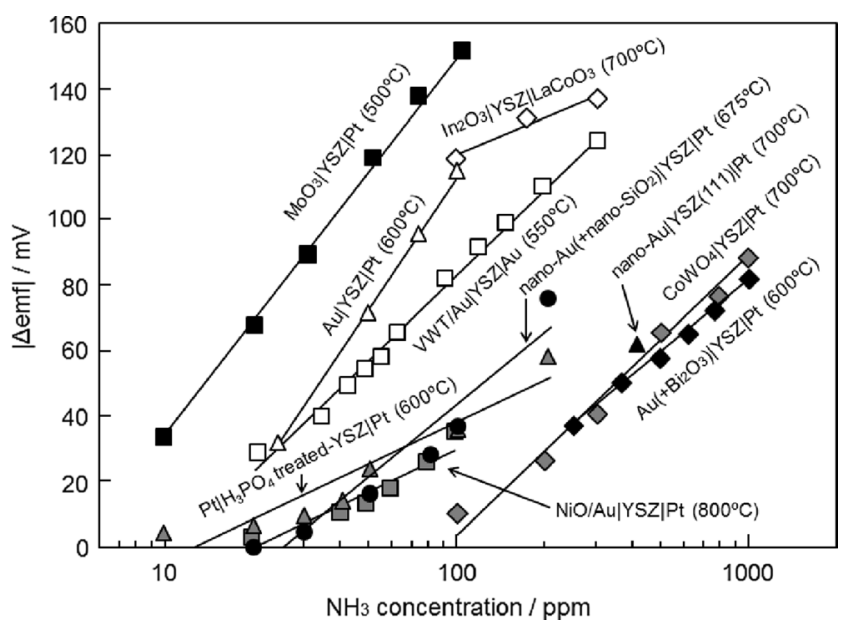

Fig. 27 Dependence of sensitivity on the logarithm of $\mathrm{NH}_{3}$ concentration for each mixed-potential type YSZ-based $\mathrm{NH}_{3}$ sensors reported so far required to have not only high sensitivity but also high selectivity to $\mathrm{NH}_{3}$. For example, Satsuma et al. reported that the acidity of $\mathrm{SE}$ materials (e.g., $\mathrm{V}_{2} \mathrm{O}_{5}, \mathrm{Bi}_{2} \mathrm{O}_{3}$, and $\mathrm{MoO}_{3}$ ) correlates with the $\mathrm{NH}_{3}$ selectivity [171]. This is due to the high basicity (high proton affinity) of $\mathrm{NH}_{3}$, which leads to an acid-base interaction between $\mathrm{SE}$ and $\mathrm{NH}_{3}$ (Fig. 25). On the same basis, Teranishi et al. have already reported that the formation of protonconducting thin film $\left(\mathrm{Zr}_{1-x} \mathrm{Y}_{x} \mathrm{P}_{2} \mathrm{O}_{7}\right)$ on the YSZ surface by the surface treatment of $\mathrm{YSZ}$ with $\mathrm{H}_{3} \mathrm{PO}_{4}$ can provide a high selectivity to $\mathrm{NH}_{3}$, since this thin film has strong acidic sites which interact with basic $\mathrm{NH}_{3}$ gas [169]. In laboratory tests, the $\mathrm{NH}_{3}$ selectivity is commonly evaluated by comparing the sensitivities of SE toward various gases. However, in a real environment, $\mathrm{NH}_{3}$ coexists with $\mathrm{HCs}, \mathrm{NO}_{x}$, and $\mathrm{CO}$ as a multi-component gaseous mixture. For example, the $\mathrm{NH}_{3}$ sensitivity of the YSZbased sensor using $\mathrm{In}_{2} \mathrm{O}_{3}$-SE was found to be largely decreased by the co-presence of $\mathrm{NO}_{2}$, since the sensitivity to $\mathrm{NO}_{2}$ is opposite to that to $\mathrm{NH}_{3}$ [62]. In order to overcome this issue, Lee et al. substituted Pt-RE in the $\mathrm{NH}_{3}$ sensor by $\mathrm{LaCoO}_{3}-\mathrm{RE}$ which gave sub-equal $\mathrm{NO}_{2}$ sensitivity to that of $\mathrm{In}_{2} \mathrm{O}_{3}$-SE. This improvement in the selection of $\mathrm{RE}$ materials enabled to minimize the negative effect of $\mathrm{NO}_{2}$ by cancelling out the $\mathrm{NO}_{2}$ sensitivity generated by $\mathrm{In}_{2} \mathrm{O}_{3}$-SE.

As summarized in Table 5, Au seems to be one of the important $\mathrm{SE}$ materials for $\mathrm{NH}_{3}$ detection. Plashnitsa et al. have reported that high $\mathrm{NH}_{3}$ selectivity can be obtained by using Au nano-particles as an SE material on the surface of the YSZ single crystal (111) [121]. In this case, interesting morphology of the nano-Au SE is observed; it consists of the triangular-like domains comprising of hundreds of nano- $\mathrm{Au}$ particles. The combination of other materials with Au-SE can also lead to the changes in $\mathrm{NH}_{3}$ sensing characteristics. For example, Elumalai et al. revealed that the lamination of thick $\mathrm{NiO}$ layer formed by a screen-printing technique on the sputtered Au-SE improved effectively both sensitivity and selectivity to $\mathrm{NH}_{3}$ for the YSZ-based sensor operated at rather 
high temperature of $800{ }^{\circ} \mathrm{C}$ [168]. Plashnitsa et al. reported that the YSZ-based sensor using nano-Au SE could provide excellent selectivity to $\mathrm{NH}_{3}$, by the modification of this $\mathrm{SE}$ with the formation of nano- $\mathrm{SiO}_{2}$ particles which were hexagonally aligned on the surface of each Au particle, as shown in Fig. 26 [172]. A strong acid-base interaction between $\mathrm{SiO}_{2}$ and $\mathrm{NH}_{3}$ was postulated to contribute for such highly selective $\mathrm{NH}_{3}$ detection.

Figure 27 summarizes and compares the $\mathrm{NH}_{3}$ sensitivities for the several above-mentioned YSZ-based sensors [57, 62, 121, 166-173]. The highest $\mathrm{NH}_{3}$ sensitivity was obtained by using the YSZ-based sensor using $\mathrm{MoO}_{3}$-SE operating at $500{ }^{\circ} \mathrm{C}$; the sensitivity $(\Delta \mathrm{emf})$ was still as high as $30 \mathrm{mV}$ even to $10 \mathrm{ppm}$ $\mathrm{NH}_{3}$ [167]. The $\Delta$ emf value of each sensor depended linearly on the logarithm of $\mathrm{NH}_{3}$ concentration in each examined range. To the common knowledge, the gas sensitivity depends on the operating temperature of sensor. At high temperature, a gasphase catalytic reaction through an SE layer will be largely facilitated, resulting in the decrease in the actual concentration of $\mathrm{NH}_{3}$ at the $\mathrm{SE} / \mathrm{YSZ}$ interface. Thus, the $\mathrm{NH}_{3}$ sensitivity is usually low at higher operating temperature. On the other hand, the lower operating temperature generally results in the higher sensitivity, while the response/recovery becomes slower as the rates of electrochemical reactions at the SE/YSZ interface decrease with lowering sensor's working temperature. Therefore, the sensor's operating temperature needs to be optimized to balance these three factors determining the sensing performances: sensitivity, selectivity, and response/recovery rates.

Both $\mathrm{Au}$ and metal oxides possessing high acidity have been considered as promising candidates for the practical SE material of the YSZ-based $\mathrm{NH}_{3}$ sensors. Further optimization of the $\mathrm{SE}$ thickness can improve the $\mathrm{NH}_{3}$ sensing characteristics. The thinner SE can improve the $\mathrm{NH}_{3}$ sensitivity, while it may bring about a decrease in $\mathrm{NH}_{3}$ selectivity. Although there have been no reports on an effective catalyst, the lamination technique of a catalyst layer on the SE layer will be an effective way to enhance the $\mathrm{NH}_{3}$ selectivity.

The final goal for the development of $\mathrm{NH}_{3}$ sensor is the utilization of the developed sensor under the real environments in automobile exhausts. Wang et al. reported on the evaluation of the performances of the developed YSZ-based $\mathrm{NH}_{3}$ sensors installed downstream of the diesel engine [175]. Ninety percent of the total $\mathrm{NO}_{x}$ was efficiently decomposed and the $\mathrm{NH}_{3}$ slip was actually suppressed within 25 ppm by feeding back a signal from the present $\mathrm{NH}_{3}$ sensor to the urea injection control system.

\section{Conclusions and future outlook}

The thriving development of zirconia-based sensors that has been elaborated in this review shows that the researches on mixed-potential type gas sensors have progressed rapidly for the past three decades. While the sensing mechanism of a mixed-potential type zirconia-based gas sensor has been clarified in the previous section, many exciting developments and groundbreaking results produced so far are evolved around the improvement in the sensing characteristics. We have reviewed key advances in sensing characteristics of zirconia-based sensors which were predominantly obtained by developing and employing highly functional electrode materials.

Recent development of high-performance zirconia-based sensors utilizing mainly the oxide-SE material is summarized in this review. Optimization on electrode functionalities was primarily achieved by either controlling the electrode morphology or by the utilization of noble metal catalyst as an additive. Satisfactory gas sensitivity was reported when $\mathrm{Au}$ was used together with the metal oxide-SE either as a catalyst layer or as an additive. However, detail elucidation on the effect of $\mathrm{Au}$ addition in gas-sensitivity enhancement of a mixed-potential type sensor has yet to be reported. Detail insight regarding the catalytic behavior of $\mathrm{Au}$ with oxide-SE would be beneficial, not only for future development of the sensor using Au with oxide-SE but also to fully understand the sensing behavior of the mixed-potential type gas sensors.

Alternative area that warrants particular attention is the gasselectivity feature. Strategies in obtaining a selective sensing signal have been reported and reviewed here. The unique approaches, such as configuration combining two electrodes, utilization of a catalyst layer coated on the SE layer, and pulsedischarge technique, were found to be effective in eliminating the interfering effects from the unwanted gases. Other important features such as lowering detection limit, accelerating the response/recovery time, and attaining long-term stability remain to be supplementary challenges that need to be conquered. The examinations of the developed zirconia-based gas sensors in real environments are definitely necessary to confirm and prove that the excellent sensing performances observed experimentally are also attainable even in real applications.

The field of mixed-potential type YSZ-based gas sensor development has an exciting future, since the need for reliable and low-cost hazardous gas detection has been increasing and expanding. The utilization of gas sensor can be predicted to have huge implication in providing safe and healthy living and working environments.

Acknowledgments This work was partially supported by JSPS KAKENHI Grant Numbers 25288109.

Open Access This article is distributed under the terms of the Creative Commons Attribution License which permits any use, distribution, and reproduction in any medium, provided the original author(s) and the source are credited. 


\section{References}

1. Stetter JR, Korotcenkov G, Zeng X, Tang Y, Liu Y (2001) Chemical sensors: comprehensive sensor technologies. In: Korotcenkov G (ed) Electrochemical and optical sensors. Momentum, New York, pp 1-89

2. Zhuiykov S, Miura N (2007) Sensors Actuators B 121:639-651

3. Potyrailo RA, Surman C, Nagraj N, Burns A (2011) Chem Rev 111: 7315-7354

4. Timmer B, Olthuis W, Van Den Berg A (2005) Sensors Actuators B 107:666-677

5. Barsan N, Koziej D, Weimar U (2007) Sensors Actuators B 121:1835

6. Wetchakun K, Samerjai T, Tamaekong N, Liewhiran C, Siriwong C, Kruefu V, Wisitsoraat A, Tuantranont A, Phanichphant S (2011) Sensors Actuators B 160:580-591

7. Fergus JW (2008) Sensors Actuators B 134:1034-1041

8. Llobet E (2013) Sensors Actuators B 179:32-45

9. Miura N, Elumalai P, Plashnitsa VV, Ueda T, Wama R, Utiyama M (2009) Solid-state electrochemical gas sensing. In: Comini E, Faglia G, Sberveglieri G (eds) Solid state gas sensing. Springer, New York, pp 181-207

10. Zhuiykov S (2007) Electrochemistry of zirconia gas sensors. CRC, Boca Raton

11. Kato N, Hamada Y, Kurachi H (1997) SAE Technical Paper 970858

12. http://www.ngkntk.co.jp/english/product/sensors/nox/index.html. Accessed 12 March 2014

13. Korotcenkov G (2005) Sensors Actuators B 107:209-232

14. Zosel J, Westphal D, Jakobs S, Müller R, Guth U (2002) Solid State Ionics 152:525-529

15. Park J, Yoon BY, Park CO, Lee WJ, Lee CB (2009) Sensors Actuators B 135:516-523

16. Sekhar PK, Brosha EL, Mukundan R, Nelson MA, Toracco D, Garzon FH (2010) Solid State Ionics 181:947-953

17. Sato T, Plashnitsa VV, Utiyama M, Miura N (2010) Electrochem Commun 12:524-526

18. Yin CG, Guan YZ, Zhu Z, Liang XS, Wang B, Diao Q, Zhang H, Ma J, Liu FM, Sun YF, Zheng J, Lu GY (2013) Sensors Actuators B 183:474-477

19. Tan Y, Tan TC (1995) Sensors Actuators B 28:113-121

20. Miura N, Lu G, Ono M, Yamazoe N (1999) Solid State Ionics 117: 283-290

21. Schmidt-Zhang P, Zhang W, Gerlach F, Ahlborn A, Guth U (2005) Sensors Actuators B 108:797-802

22. Yang JC, Dutta PK (2007) Sensors Actuators B 123:929-936

23. Ueda T, Nagano T, Okawa H, Takahashi S (2009) Electrochem Commun 11:1654-1656

24. Miura N, Nakatou M, Zhuiykov S (2003) Sensors Actuators B 93: 221-228

25. Wama R, Plashnitsa VV, Elumalai P, Utiyama M, Miura N (2010) Solid State Ionics 181:359-363

26. Woo LY, Glass RS, Novak RF, Visser JH (2011) Sensors Actuators B 157:115-121

27. Wang L, Hao ZC, Dai L, Li YH, Zhou HZ (2012) Mater Lett 87:24 27

28. Liu YX, Lei Y (2013) Sensors Actuators B 188:1141-1147

29. Miura N, Lu GY, Yamazoe N (2000) Solid State Ionics 136:533542

30. Fergus JW (2007) Sensors Actuators B 122:683-693

31. Fleming WJ (1977) J Electrochem Soc 124:21-28; Pebler AR (1977). US patent 4005001

32. Shimizu F, Yamazoe N, Seiyama T (1978) Chem Lett 7:299-300

33. Okamoto H, Obayashi H, Kudo T (1980) Solid State Ionics 1:319326

34. Okamoto H, Obayashi H, Kudo T (1981) Solid State Ionics 3-4: 453-456
35. Moseley PT, Tofield BC (1987) Solid state gas sensors. Adam Hilger, Bristol

36. Vogel A, Baier G, Schule V (1993) Sensors Actuators B 15:147150

37. Li N, Tan TC, Zeng HC (1993) J Electrochem Soc 140:1068-1073

38. Tan Y, Tan TC (1994) J Electrochem Soc 141:461-467

39. Narducci D, Ornaghi A, Mari CM (1994) Sensors Actuators B 19: 566-568

40. Can ZY, Narita H, Mizusaki J, Tagawa H (1995) Solid State Ionics 79:344-348

41. Mcaleer JF, Moseley PT, Williams DE, Maignan A (1989) Sensors Actuators 17:313-318

42. Mcaleer JF, Maignan A, Moseley PT, Williams DE (1989) J Chem Soc Faraday Trans 85:783-799

43. Miura N, Yan Y, Lu G, Yamazoe N (1995) Proc of 8th Int Conf on Solid-state Sens Actuators Eurosensors IX 2:453-410D

44. Miura N, Lu GY, Yamazoe N, Kurosawa H, Hasei M (1996) J Electrochem Soc 143:L33-L35

45. Miura N, Kurosawa H, Hasei M, Lu GY, Yamazoe N (1996) Solid State Ionics 86-8:1069-1073

46. Miura N, Yan YT, Lu GY, Yamazoe N (1996) Sensors Actuators B 34:367-372

47. Lu GY, Miura N, Yamazoe N (1996) J Electrochem Soc 143:L154 L155

48. Jakobs S, Hartung R, Lawrenz U, Sandow P, Schonauer U, Guth U (1996) Ionics 2:451-458

49. Sorita R, Kawano T (1996) Sensors Actuators B 36:274-277

50. Sorita R, Kawano T (1997) Sensors Actuators B 40:29-32

51. Hashimoto A, Hibino T, Mori KT, Sano M (2001) Sensors Actuators B 81:55-63

52. Szabo NF, Dutta PK (2004) Solid State Ionics 171:183-190

53. Grilli ML, Di Bartolomeo E, Lunardi A, Chevallier L, Cordiner S, Traversa E (2005) Sensors Actuators B 108: 319-325

54. Brosha EL, Mukundan R, Lujan R, Garzon FH (2006) Sensors Actuators B 119:398-408

55. Li XG, Kale GM (2007) Sensors Actuators B 123:254-261

56. Zosel J, Tuchtenhagen D, Ahlborn K, Guth U (2008) Sensors Actuators B 130:326-329

57. Schönauer D, Wiesner K, Fleischer M, Moos R (2009) Sensors Actuators B 140:585-590

58. Fujio Y, Plashnitsa VV, Elumalai P, Miura N (2011) Talanta 85:575581

59. Macam ER, Blackburn BM, Wachsman ED (2011) Sensors Actuators B 157:353-360

60. Gao J, Viricelle JP, Pijolat C, Breuil P, Vernoux P, Boreave A, Giroir-Fendler A (2011) Sensors Actuators B 154:106-110

61. Mori M, Itagaki Y, Sadaoka Y (2012) Sensors Actuators B 161: 471-479

62. Lee I, Jung B, Park J, Lee C, Hwang J, Park CO (2013) Sensors Actuators B 176:966-970

63. Kim ID, Rothschild A, Tuller HL (2013) Acta Mater 61:974-1000

64. Guan YZ, Yin CG, Cheng XY, Liang XS, Diao Q, Zhang H, Lu GY (2014) Sensors Actuators B 193:501-508

65. Miura N, Kato H, Yamazoe N, Seiyama T (1982) Denki Kagaku 50: 858-859 (in Japanese)

66. Miura N, Kato H, Yamazoe N, Seiyama T (1983) Chem Lett 12: $1573-1576$

67. Miura N, Kato H, Yamazoe N, Seiyama T (1986) Fund Appl Chem Sens 203

68. Miura N, Kaneko H, Yamazoe N (1987) J Electrochem Soc 134: 1875-1876

69. Miura N, Yamazoe N (1992) Solid State Ionics 53:975-982

70. http://www.kidde.com/ProductCatalog/Pages/ CarbonMonoxideAlarmsBattery Powered.aspx - .UsvFstJdW8A. Accessed 12 March 2014 
71. http://www.figarosensor.com/products/5042pdf.pdf. Accessed 12 March 2014

72. Miura N, Jin H, Wama R, Nakakubo S, Elumalai P, Plashnitsa VV (2011) Sensors Actuators B 152:261-266

73. Jin H, Breedon M, Plashnitsa VV, Miura N (2012) J Electrochem Soc 159:B801-B810

74. http://www.ngkntk.co.jp/english/product/sensors/zirconia/index. html. Accessed 12 March 2014

75. Liang XS, Yang SQ, Li JG, Zhang H, Diao Q, Zhao W, Lu GY (2011) Sensors Actuators B 158:1-8

76. Elumalai P, Wang J, Zhuiykov S, Terada D, Hasei M, Miura N (2005) J Electrochem Soc 152:H95-H101

77. Sato T, Breedon M, Miura N (2013) J Electrochem Soc 160:B146B151

78. Garzon FH, Mukundan R, Lujan R, Brosha EL (2004) Solid State Ionics 175:487-490

79. Sekhar PK, Sarraf H, Mekonen H, Mukundan R, Brosha EL, Garzon FH (2013) Sensors Actuators B 177:111-115

80. Yang JC, Dutta PK (2007) Sensors Actuators B 125:30-39

81. Hasei M, Ono T, Gao Y, Yan Y, Kunimoto A (2000) SAE Technical Paper Series 01-1203:1-7

82. Ono T, Hasei M, Kunimoto A, Miura N (2004) Solid State Ionics 175:503-506

83. Lu GY, Miura N, Yamazoe N (1996) Sensors Actuators B 35:130135

84. Miura N, Raisen T, Lu G, Yamazoe N (1998) Sensors Actuators B 47:84-91

85. Garzon FH, Mukundan R, Brosha EL (2000) Solid State Ionics 136: 633-638

86. Anggraini SA, Breedon M, Ikeda H, Miura N (2013) ACS Appl Mater Int 5:12099-12106

87. Chevallier L, Di Bartolomeo E, Grilli ML, Mainas M, White B, Wachsman ED, Travers E (2008) Sensors Actuators B 129:591-598

88. Van Assche FM, Wachsman ED (2008) Solid State Ionics 179: 2225-2233

89. Macam ER, Blackburn BM, Wachsman ED (2011) Sensors Actuators B 158:304-312

90. Mori M, Nishimura H, Itagaki Y, Sadaoka Y (2009) Sensors Actuators B 142:141-146

91. Mori M, Sadaoka Y (2010) Sensors Actuators B 146:46-52

92. Okamoto H, Kawamura G, Kudo T (1983) J Catal 82:322-331

93. Katsumoto M, Okamoto H, Kobayashi M (1985) Denki Kagaku 53: 577-581

94. Plashnitsa VV, Anggraini SA, Miura N (2011) Electrochem Commun 13:444-446

95. Striker T, Ramaswamy V, Armstrong EN, Willson PD, Wachsman ED, Ruud JA (2013) Sensors Actuators B 181:312-318

96. Brosha EL, Mukundan R, Brown DR, Garzon FH (2002) Sensors Actuators B 87:47-57

97. Brosha EL, Mukundan R, Brown DR, Garzon FH, Visser JH, Zanini M, Zhou Z, Logothetis EM (2000) Sensors Actuators B 69:171-182

98. Morata A, Viricelle JP, Tarancon A, Dezanneau G, Pijolat C, Peiro F, Morante JR (2008) Sensors Actuators B 130:561-566

99. Giang HT, Duy HT, Ngan PQ, Thai GH, Thu DTA, Thu DT, Toan NN (2013) Sensors Actuators B 183:550-555

100. Wu RJ, Hu CH, Yeh CT, Su PG (2003) Sensors Actuators B 96: 596-601

101. Anggraini SA, Plashnitsa VV, Elumalai P, Breedon M, Miura N (2011) Sensors Actuators B 160:1273-1281

102. Fujio Y, Plashnitsa VV, Breedon M, Miura N (2012) Langmuir 28: $1638-1645$

103. Hibino T, Hashimoto A, Kakimoto S, Sano M (2001) J Electrochem Soc 148:H1-H5

104. Mochizuki K, Sorita R, Takashima H, Nakamura K, Lu G (2001) Sensors Actuators B 77:190-195
105. Hibino T, Kakimoto S, Sano M (1999) J Electrochem Soc 146: 3361-3366

106. Westphal D, Jakobs S, Guth U (2001) Ionics 7:182-186

107. Müller R, Zosel J, Ahlborn K, Guth U (2002) Ionics 8:262-266

108. Zosel J, Ahlborn K, Müller R, Westphal D, Vashook V, Guth U (2004) Solid State Ionics 169:115-119

109. Elumalai P, Plashnitsa VV, Ueda T, Miura N (2008) Electrochem Commun 10:745-748

110. Mori M, Nishimura H, Itagaki Y, Sadaoka Y, Traversa E (2009) Sensors Actuators B 143:56-61

111. Sato T, Plashnitsa VV, Utiyama M, Miura N (2011) J Electrochem Soc 158:J175-J178

112. Suetsugu Y, Sato T, Breedon M, Miura N (2012) Electrochim Acta $73: 118-122$

113. Ueda T, Elumalai P, Plashnitsa VV, Miura N (2008) Chem Lett 37: $120-121$

114. Wama R, Plashnitsa VV, Elumalai P, Kawaguchi T, Fujio Y, Utiyama M, Miura N (2009) J Electrochem Soc 156:J102-J107

115. Hibino T, Tanimoto S, Kakimoto S, Sano M (1999) Electrochem Solid State 2:651-653

116. Inaba T, Saji K, Sakata J (2005) Sensors Actuators B 108:374-378

117. Elumalai P, Plashnitsa VV, Fujio Y, Miura N (2010) Sensors Actuators B 144:215-219

118. Hibino T, Wang SQ, Kakimoto S, Sano M (1998) Sensors Actuators B 50:149-155

119. Miura N, Shiraishi T, Shimanoe K, Yamazoe N (2000) Electrochem Commun 2:77-80

120. Chevallier L, Di Bartolomeo E, Grilli ML, Traversa E (2008) Sensors Actuators B 130:514-519

121. Plashnitsa VV, Elumalai P, Fujio Y, Miura N (2009) Electrochim Acta 54:6099-6106

122. Chevallier L, Traversa E, Di Bartolomeo E (2010) J Electrochem Soc 157:J386-J391

123. Sekhar PK, Mukundan R, Brosha E, Garzon F (2013) Sensors Actuators B 183:20-24

124. Riegel J, Neumann H, Wiedenmann HM (2002) Solid State Ionics 152:783-800

125. Lu G, Miura N, Yamazoe N (1997) J Mater Chem 7:1445-1449

126. Hibino T, Kuwahara Y, Otsuka T, Ishida N, Oshima T (1998) Solid State Ionics 107:217-220

127. Lu G, Miura N, Yamazoe N (2000) Sensors Actuators B 65:125127

128. Zhuiykov S, Nakano T, Kunimoto A, Yamazoe N, Miura N (2001) Electrochem Commun 3:97-101

129. Zhuiykov S, Ono T, Yamazoe N, Miura N (2002) Solid State Ionics 152:801-807

130. Miura N, Zhuiykov S, Ono T, Hasei M, Yamazoe N (2002) Sensors Actuators B 83:222-229

131. Dutta A, Kaabbuathong N, Grilli ML, Di Bartolomeo E, Traversa E (2003) J Electrochem Soc 150:H33-H37

132. Kading S, Jakobs S, Guth U (2003) Ionics 9:151-154

133. Martin LP, Pham AQ, Glass RS (2003) Sensors Actuators B 96:5360

134. Ono T, Hasei M, Kunimoto A, Miura N (2003) Electrochemistry 71: 405-407

135. Di Bartolomeo E, Kaabbuathong N, D'Epifanio A, Grilli ML, Traversa E, Aono H, Sadaoka Y (2004) J Eur Ceram Soc 24: $1187-1190$

136. Miura N, Akisada K, Wang J, Zhuiykov S, Ono T (2004) Ionics 10: $1-9$

137. Di Bartolomeo E, Grilli ML, Traversa E (2004) J Electrochem Soc 151:H133-H139

138. Di Bartolomeo E, Kaabbuathong N, Grilli ML, Traversa E (2004) Solid State Ionics 171:173-181

139. Elumalai P, Miura N (2005) Solid State Ionics 176:2517-2522

140. Xiong WZ, Kale GM (2006) Sensors Actuators B 114:101-108 
141. Plashnitsa VV, Ueda T, Elumalai P, Kawaguchi T, Miura N (2008) Ionics 14:15-25

142. Plashnitsa VV, Elumalai P, Miura N (2008) J Electrochem Soc 155: J301-J306

143. Zosel J, Franke D, Ahlborn K, Gerlach F, Vashook V, Guth U (2008) Solid State Ionics 179:1628-1631

144. Elumalai P, Zosel J, Guth U, Miura N (2009) Ionics 15:405-411

145. Elumalai P, Plashnitsa VV, Fujio Y, Miura N (2009) J Electrochem Soc 156:J288-J293

146. Breedon M, Zhuiykov S, Miura N (2012) Mater Lett 82:51-53

147. Diao Q, Yin CG, Guan YZ, Liang XS, Wang S, Liu YW, Hu YF, Chen H, Lu GY (2013) Sensors Actuators B 177:397-403

148. Diao Q, Yin CG, Liu YW, Li JG, Gong X, Liang XS, Yang SQ, Chen H, Lu GY (2013) Sensors Actuators B 180:90-95

149. Miura N, Wang J, Nakatou M, Elumalai P, Zhuiykov S, Hasei M (2006) Sensors Actuators B 114:903-909

150. Wang J, Elumalai P, Terada D, Hasei M, Miura N (2006) Solid State Ionics 177:2305-2311

151. Lopez-Gandara C, Fernandez-Sanjuan JM, Ramos FM, Cirera A (2011) Solid State Ionics 184:83-87

152. Lu G, Miura N, Yamazoe N (1998) Ionics 4:16-24

153. Plashnitsa VV, Gupta V, Miura N (2010) Electrochim Acta 55: 6941-6945

154. Breedon M, Miura N (2013) Sensors Actuators B 182:40-44

155. Fadeyev G, Kalakin A, Demin A, Volkov A, Brouzgou A, Tsiakaras P (2013) Int J Hydrog Energy 38:13484-13490

156. Martin LP, Glass RS (2005) J Electrochem Soc 152:H43-H47

157. Martin LP, Pham AQ, Glass RS (2004) Solid State Ionics 175:527-530

158. Zosel J, Schiffel G, Gerlach F, Ahlborn K, Sasum U, Vashook V, Guth U (2006) Solid State Ionics 177:2301-2304

159. Sekhar PK, Brosha EL, Mukundan R, Nelson MA, Williamson TL, Garzon FH (2010) Sensors Actuators B 148:469-477

160. Sekhar PK, Brosha EL, Mukundan R, Mekonen H, Farber B, Kreller C, Garzon FH (2012) Int J Hydrog Energy 37:14707-14713

161. Yamaguchi M, Anggraini A, Fujio Y, Breedon M, Plashnitsa VV, Miura N (2012) Electrochim Acta 76:152-158

162. Yamaguchi M, Anggraini SA, Fujio Y, Sato T, Breedon M, Miura N (2013) Int J Hydrog Energy 38:305-312
163. Anggraini SA, Breedon M, Miura N (2013) Electrochem Commun 31:133-136

164. Fischer S, Pohle R, Farber B, Proch R, Kaniuk J, Fleischer M, Moos R (2010) Sensors Actuators B 147:780-785

165. http://www.scf.co.uk/SCRpaperfinal(ACEA).pdf. Accessed 12 March 2014

166. Schönauer-Kamin D, Fleischer M, Moos R (2013) Sensors 13: $4760-4780$

167. Kida T, Kawasaki K, Iemura K, Teshima K, Nagano M (2006) Sensors Actuators B 119:562-569

168. Elumalai P, Plashnitsa VV, Fujio Y, Miura N (2008) Electrochem Solid State 11:J79-J81

169. Teranishi S, Kondo K, Nishida M, Kanematsu W, Hibino T (2009) Electrochem Solid State 12:J73-J76

170. Sekhar PK, Brosha EL, Mukundan R, Li WX, Nelson MA, Palanisamy P, Garzon FH (2010) Sensors Actuators B 144:112119

171. Satsuma A, Katagiri M, Kakimoto S, Sugaya S, Shimizu K (2011) Sensors 11:2155-2165

172. Plashnitsa VV, Elumalai P, Fujio Y, Kawaguchi T, Miura N (2011) Nanoscale 3:2286-2293

173. Diao Q, Yang FS, Yin CG, Li JG, Yang SQ, Liang XS, Lu GY (2012) Solid State Ionics 225:328-331

174. Busca G, Lietti L, Ramis G, Berti F (1998) Appl Catal B Environ 18:1-36

175. Wang D, Yao S, Shost M, Yoo J, Cabush D, Racine D, Cloudt R, Willems F (2009) SAE Int J Passenger Cars Electron Electr Syst 1: 323-333

176. Park JY, Song SJ, Wachsman ED (2010) J Am Ceram Soc 93:1062_ 1068

177. Sun FJ, Li XG, Liu LP, Wang J (2013) Sensors Actuators B 184: 220-227

178. Thiemann S, Hartung R, Guth U, Schonauer U (1996) Ionics 2:463467

179. Mukundan R, Brosha EL, Garzon FH (2003) J Electrochem Soc 150:H279-H284

180. Anggraini SA, Breedon M, Miura N (2013) J Electrochem Soc 160: B164-B169 